\title{
The Sixth Sense-Emotional Contagion; Review of Biophysical Mechanisms Influencing Information Transfer in Groups
}

\author{
Alan McDonnell \\ Emergent Dynamic Technologies Ltd., Bristol, UK \\ Email: Alan@emergentdynamictechnologies.co.uk
}

Received 25 May 2014; revised 10 July 2014; accepted 26 July 2014

Copyright (C) 2014 by author and Scientific Research Publishing Inc.

This work is licensed under the Creative Commons Attribution International License (CC BY). http://creativecommons.org/licenses/by/4.0/

c) (i) Open Access

\section{Abstract}

Rioting historically has been known to cause changes in individual cognition, with heightened emotionality, increased excitement and reduced reflective thought. A cross-disciplinary literature review hypothesises emotional states generate corresponding metabolic bio magnetic fields that radiate in patterns reflecting these emotional states. The oscillatory phase of these waves is advanced as being more significant than the power of signal, permitting stochastic effects to magnify signals by appropriating ambient noise. Possible transmission and detection structures in the body are discussed, induced paramagnetic sensitivity in crowd participants in a phase transition process is hypothesised, the effect may be proportional to crowd numbers. It is suspected that positive effects seen in Transcranial Magnetic Therapy used to treat depression may be operating on this mechanism, acting on natural receptors in the limbic system which also capture light and are implicated in mood transitions. A number of paramagnetic neurotransmitters may be implicated.

\section{Keywords}

Behaviour, Crowds, Harmonic, Oscillation, Stochastic, Synchronization

\section{Overview}

\subsection{Underlying Mechanisms}

Group behaviours have profound consequences for human society, whether in stock market panics, revolutionary politics, expressions of religious belief or in public order situations Commentators noted emotionality in groups overriding logical individual thinking; "the unreal has about as much influence on them as the real.” Le- 
Bon, [1] stated when considering crowd behaviour. Mechanisms of crowd behaviour are influenced by a multitude of variable factors which have provoked controversy amongst researchers in the Humanities as to their significance.

It is not only in human crowds that it is possible to see group behaviours; flocking is common in insects, birds, and fish as well as people, suggesting a search for a common physical mechanism may be fruitful. Human flocking behaviour is expressed when a crowds mood quickly changes to become a mob through sudden changes in group behaviour, as noted in flashpoint theory [2]-[6].

While there is some agreement that these behaviours appear to be linked to both intensity of feeling and presence of threat, there is disagreement over the importance of many other contributory factors; culture, poverty, education, economics and globalisation have all been suggested as significant.

These superficially differing concepts may be driven by more fundamental physical power laws expressed in the development of the human body through evolution. To understand these requires identification of possible underlying properties of the body. It is suggested that the brain functions using oscillation of neural signals and stochastic resonance, [7] as biophysical data transfer mechanisms. This involves ambient energy (background "noise") being used by the body to amplify and carry emotional data between people in routine interactions. The strength of such signals may be amplified in emotionally charged crowd situations to levels where individual decision making may be influenced and entrained by the presence of others.

The concepts of biomagnetic resonance and stochastic resonance are proposed as possible means of such a data transfer. Biomagnetic resonance is understood to be the biomagnetic energy field produced by metabolism in the body which is radiated away from the body, stochastic resonance is understood (for the purpose of this work), to be the ability of a signal to absorb power from its background environment while maintaining coherence in its meaning, multiplying in this way the strength of its signal.

It is argued that biomagnetic resonance carries patterns produced by the metabolic state of the body, reflecting the emotional state. These signals are proposed to be then amplified by stochastic resonation and to be detectable in others. In group situations it is suspected to lead to unconscious data transfer capable of initiating a phase transition from individual thought to a mob mentality where fight or flight reflexes predominate.

It is possible that positive effects seen in Transcranial Magnetic Therapy used to treat depression may be operating on this mechanism, acting on natural receptors in the limbic system which also capture light and are implicated in mood transitions.

\subsection{Method}

For the purpose of this work a person is considered to be a crowd member when he or she is reacting collectively with others experiencing the same or similar emotional states, some form of data transfer between crowd members is implicit. This work is intended to be a cross disciplinary research review across a number of fields influencing collective cognition in order to identify this anomaly. Commonalities in mechanisms of data transfer and processing group behaviours shared between both animals and humans are considered as a central hypothesis, as it appears that humans may have retained physical structures and emotional response structures from more primitive common evolutionary ancestors.

To understand what physically a crowd is, how data flows physically between crowd members, and how crowd members exist in multidimensional space, a range of new research from materials science and Physics has been used. This involved a literature review across a number of different disciplines previously not extensively examined by criminology to explain changes in thinking during crowd events.

In violent crowds, we see behavioural changes through heightened emotions, impulsiveness, speed of reaction, and increased aggression, [8] all these behaviours are typical of using unconscious rather than conscious thought processes. The role of sight and sound are approximately known in a large number of works examining how they influence crowd behaviour, therefore when searching to understand additional cognitive anomalies such as sudden mood changes in groups, it suggests supplementary factor/s are changing thinking in crowds. This work is intended to be a cross disciplinary research review across a number of fields influencing collective cognition in order to identify this anomaly. Commonalities in mechanisms of data transfer and processing group behaviours shared between both animals and humans are considered as a central hypothesis, as it appears that humans may have retained physical structures and emotional response structures from more primitive common evolutionary ancestors.

Understanding a crowd as an emergent non-linear emergent phenomenon has been used as crowds will always 
be unique to some degree due to every crowd being composed of unique individuals. While they may retain similarities from one day to the next, crowd members will also never have exactly the same state of mind, as their experiences are constantly transforming them, and therefore their subsequent reactions to environmental stimuli.

For the purpose of this work a person is considered to be a crowd member when he or she is reacting collectively with others experiencing the same or similar emotional states, some form of data transfer between crowd members is implicit. Concerning mechanisms of data transfer across the electromagnetic spectrum between people, this work is especially focused to outline and understand the large number of emergent processes proposed to be involved in these data transfers, which may cause significant degrees of fluctuation and variability in behaviour. The extreme variability and emergent nature of the large number of inputs into any crowds state of mind implies that rather than establishing a traditional model of experimentally replicable results, identification of similarities in types of cognitive process gives more insight into predicting crowd behaviours.

\section{Crowds and Mobs}

\subsection{Introduction}

Differences in behaviour in crowd members acting collectively compared to how individuals behave has been widely noted, from Smelser [9], Cannetti [10] and more recently Reicher [11]-[13]. Although most crowds demonstrate restraint, this work is less concerned with these, as they demonstrate less signs of the co-ordination that crowds appear to demonstrate under emotionally charged situations.

Recent rioting in the summer of 2011 in the UK as well as many previous incidents of disorder provided many anecdotes of people taking irrational decisions leading them to participate in rioting and looting. While a majority of rioters were persons known to Police, Ministry of Justice data suggested that while $76 \%$ of suspects had a previous caution or conviction [14], 24\% appeared to be without previous convictions and following their arrest, lost jobs and career prospects; often for the theft of items of minor value.

These decisions exposed the rioters to considerable future down sides in their daily lives as well as minimal benefits if they were undetected. The inference for this type of distorted cognition appears to be that there is something sporadically affecting cognition specifically in emotional groups of people. Recent criminology has advanced different groups, ideas, policies or economic systems as explaining public disorders since the 1940's to present day. Episodic emotionally influenced group behaviours seen in public disorders have been seen not only in the 21st and 20th Centuries, but for thousands of years under a multiplicity of different political, religious, social and economic systems, therefore sociological explanations do not appear to be able to explain this effect.

This effect appears to act as a type of temporary reversible mental handicap. That some are more prone to this affect than others indicates that there may be a physiological component to their vulnerability. There are several variables possibly affecting the strength of this effect; physical proximity to others, crowd size, emotional characteristics of others and possibly environmental location and ambient factors. Due to the complexity of the human body further research will be necessary to be more precise as to understanding the degree of individual variations in sensitivity.

People do not appear to take decisions in the same way when feeling strong emotions in the proximity of others as they do on their own [15] [16], it appears that bigger the crowd is, the stronger the affect appears to be, suggesting a physical mechanism of data transfer. Anomalies from anecdotes of crowd behaviour by Police suggested an additional factor in crowd behaviour as well as influences from sight and sound. Demonstrators can spend hours listening to verbal protests with minimal responses, but a sudden change in mood causes a rapid transition to physical violence on small stimuli. A verbal request for action is suddenly evaluated as significant and responded to by the crowd where all previous appeals for action were ignored. Something therefore appears to have changed in the crowd's cognitive process. "At several of the riots last week, those perpetrating the violence had no ready explanation for their behaviour. One young man, kicking trash cans into the street, shrugged when asked why. And the atmosphere in Hackney's Pembury Road low-income housing projects was sometimes one of adrenaline-driven glee. Looters whooped as they stripped a convenience store bare, yards from the police. Even some Londoners who had initially condemned the riotous behaviour joined in." [17].

It became apparent during this review that the human body has retained structures in the body and brain originating from more primitive ancestors, and possibly in stressful situations these structures are inferred to be capable of being used by the unconscious to sporadically absorb data via biomagnetic emissions. These metabolic energy emissions are inferred to carry patterns reflecting the emotional state of the body and are radiated 
away from the body, when detected above a certain level, may be inducing a tipping point in cognitive salience for emotion related data

Part of this spectrum of data radiation is electromagnetic; magnetic signals are used in MRI scanners due to their ability to go through tissue with minimum distortion. Due to this characteristic of electromagnetic waves and a phenomenon known as Stochastic Resonance, low power signals are proposed to be detectable by others. This may be through an unconscious cognition process feeding into fight or flight related centres of the brain [18] to activate unconscious reflexive mental states appropriate for responses to crisis situations.

As this is proposed to be a complex phenomenon involving a large number of emergent systems, variables and inputs, this will be discussed in further detail.

\subsection{Discussion}

Previous research into interpersonal communication has been centered around the obvious media of light, sound, smell, thermal sensitivity and touch, which are easily perceived and shared across species. It is known that all these senses gather and transfer environmentally relevant information to the brain for processing, contributing to a consolidated flow of information or stream of consciousness from which decision making emerges. It is also known that unconsciously perceived information from the environment contributes to this stream of consciousness. Other parts of the energy spectrum, which are not visible may also carry enough information between organisms to be interpreted subconsciously, elephants are known to be able to sense approaching animals from miles away through kinetic vibration through the ground [19].

\section{Sight}

\subsection{Focus of Attention, Fear Activation}

Sight is known to play an important role in starting crowd behaviour, it is known that a shared focus of attention is one of the first signs of a group forming. When and why a crowd forms is subject to a number of factors, unfortunately for researchers in the field these factors are all dynamic, emergent and impossible to experimentally replicate in exactly the same way under laboratory conditions, especially during a riot.

Fear appears to be a key criteria for initiation of increased attention, research indicates it is activated by perception of difference in others flagged in the in the unconscious activating previously accumulated stereotypes, [20] [21]. Some researchers indicated perception of data invoking fear activates the amygdale/habenula, it is believed to start unconscious reflexive routines giving greater speed in scanning, decision making [22], unconscious synchronisation of eye movements (saccades), gestures and facial muscles [23].

Other research disagreed, and suggested the other subcortical structures (such as the pulvinar) or areas within the cortex [24] as being responsible. However, all these behaviours appear to be signs of a group action effect being established, [25]. Fear evoking criteria includes subconscious detection of difference such as ethnicity, sex, and visible signs of religious or philosophical adherence in others [26] [27].

There is evidence that the mind is sensitised to signs that others are not like us, [28] and therefore others differences may be automatically evaluated as potentially hostile. It was [29] proposed that the subconscious takes over in danger related situations, being from another group implies a potential competition and threat. Unconscious evaluation may also infer that an absence of mimicry and synchronisation in others is interpreted reflexively in the unconscious as hostility.

\subsection{Unconscious Environmental Scanning}

As well as searching for differences in others, we may also be looking for commonalities in those around us. As well as differences, the mind appears to search for similarities; processes in the unconscious scan the environment to match people who have similarities to us who may be part of our group and be able to help us. Perception of similarities in others in the unconscious may lower inter group aggression and help co-operation, an interesting area for future experimentation.

As well as searching for differences in others, we may also be looking for commonalities in those around us. If we are likely to be attacked by a group of different "others", we have an evolutionary need to co-ordinate our own group of "us" to resist, focussed attention may also be searching for commonalities in those nearby to see if they will help us. The compatibility principle [30] states that individual agents will only form information ex- 
change relationships on the basis of the relevant parties having sufficient mutually recognisable compatibility, it appears that the initial visual focus of attention may also be for the purpose of evaluating whether this exists or not.

It has been [31] suggested there are two separate neural systems the unconscious uses to scan faces; one system spots physiological features that are emotional (e.g., identity, gender, race), the other examines exterior or dynamic expressions (e.g., quick displays of emotions), their research proposes that these two neural systems interact in a bi-directional manner. It may be the system identifying stable difference may work first, then activating the dynamic system to examine the emotional state of the person found to be different. This bi-directionality will be mentioned later regarding signal oscillation as a feature of hypothesised interpersonal synchronisation mechanisms.

\subsection{Focus of Attention}

The focus of attention mechanism is a hardwired in humans, and implicated in the first stage of crowd formation. Research [32] indicated babies are able to synchronise their gaze with their mothers rapidly from birth. It is also the starting point for communal behaviours. Even though crowds are emergent processes, it can be said to have a phase transition moment when it forms. It appears to be sufficient for a group of people to mutually focus their attention on the same object to start some degree of collective behaviours [33] [34]. Shared attentional focus appears to initiate a phase transition in mental processing, phase transitions appear strongly involved in neuronal oscillations in the brain as a basic functional process, [35] and are therefore significant in both detection of potential threats in the vicinity [36] and decision making.

Focus of attention activates the right prefrontal dorsolateral cortex [37], involved in executive control resources, while itself more evolutionarily recent, this region of the brain connects to one of the most ancient parts of the brain stem linked to motor function. There are many shared structural similarities between human brain stems and a wide range of other organisms, which also display communal behaviour similar to human crowds.

There may be a dual function in the optic nerves, [38] it was proposed the ophthalmic branch of the trigeminal nerve were sensitive to small magnetic fluctuations as well as light, citing [39] work indicating a diffused magnetic remanence (remanence; that a protein after being exposed to a magnetic field remains magnetised even after the initial field ceases), it would appear that sight may play a role in initiating magneto sensitivity, photons are force carriers for electromagnetic waves.

The hypothalamus appears significant, "Animal studies done in the 1970s, have shown that there is a direct visual input from the retina to the limbic system, also known as the centre of emotions. This suggests that light cues may affect emotional behaviour. Furthermore, it has been shown that the limbic and preoptic systems project to brain areas that play key roles in the arousal system, such as the lateral hypothalamus (LHA), orexin neurons and the locus coeruleus $(L C)$. These neural connections from retina via the limbic system to the arousal system exist but they have never been discussed from a light-induced alertness point of view" [40]. It is suggested that light can pass via the amygdala in the limbic system to send signals to the cerebral cortex. The participation of the amygdala in light-induced alertness implies that "light is provoking and modulating emotions that induce alerting responses" [41]. While these channels are identified as being light carrying, as light and electromagnetism are dual aspects of one energy system, magnetic waves are also implicitly carried.

\subsection{Stream of Consciousness from Environmental Data}

Sight plays a role in conjunction with other senses to create a stream of data inputs to the unconscious mind, for decision making. The quantum observer effect is that the act of looking at something changes the object being looked at, see [42]. This provides a theoretical communications channel between entangled systems, i.e. people in a crowd, this hypothesis will be challenging experimentally in quantifying what could be an electromagnetic data transfer and what could be quantum entanglement.

\section{Identification of Data Transfer Channels}

\subsection{Communication in Confusing Environments}

Crowds appear to experience mood changes in many different environments that can interfere with transmission of sight and sound, darkness, noise, smoke and weather can all interfere with an awareness of what is going on 
nearby. The gap in current knowledge can be said to be regarding what forms of data transfer transforms moods and emotion as it is this which effects changes in crowd behaviours. With this in mind, it was noted that patients who had MRi scans experienced effects which gave a clue as to what physical factor could influence crowd emotions. Patients undergoing Magnetic Resonance Imaging scans during cancer treatment were exposed to strong magnetic fields. During these scans, those patients suffering from chronic depression had improvements in mood lasting up to a month following MRi treatment. This provides a clue that magnetic fields can therefore be shown to affect mood [43].

This effect is now being used as a therapy, (Trans Cranial Magnetic stimulation, "There is enough evidence of the efficacy and safety of TMS in depression to include this technique in the therapeutic protocols of major depression." [44].

Other sources of magnetism which may be present in crowd situations are electrical equipment signals (which do not usually fluctuate), mobile phones (both of which were not present in crowd situations with similar behaviours in historical events) and geomagnetic and atmospheric magnetic fields.

\subsection{Characteristics of Human Biomagnetism}

People also radiate magnetic fields as a side effect of the body's normal metabolic processes [45]. These fields are far weaker than those emitted by MRI scanners and are at the nano/pico tesla level, but may contain uniquely organic signatures, it is known that the body is sensitive even to these low power levels [46]. Human physiology may be also susceptible to natural magnetic fluctuations [47] which may affect mood, there appears to be a generalised sensitivity to ambient magnetic fields [48], other humans biomagnetic emissions may be considered another input to the ambient field. Even muscle movements generate electricity; low-frequency electric fields were induced by natural body movements while patients were in MRi scanners [49].

Human biomagnetic emissions reflect the emotional state of the individual due to the link between the emotions and the heart rate [50], when we are angry our metabolism speeds up as we get ready to fight or run. The magnetic part of the spectrum has a frequency range which operates at the same frequencies that brainwaves are known to function at in thinking processes. Biomagnetic fields radiate some distance from the body, if crowd members are angry or fearful, their biomagnetic resonation away from the body will logically carry patterns containing this data as the body produces a bio-magnetic field with patterns corresponding to its metabolic condition.

\section{What Makes a Crowd}

\subsection{Synchronisation between Crowd Members}

As mentioned, synchronisation of body language and eye movements and behaviours takes place between crowd members [51]-[54]. People in closer physical proximity to each other and in an emotionally exited state (for whatever reason) are hypothesised as not only be able (at some stage) to see and hear the objects of common focus, but also to be best positioned to be able to pick up additional signals from each others biomagnetic emissions. If they experience a predominant emotion/s together they may also produce a larger collective biomagnetic output signal potentially detectable further away. It would appear that biomagnetic sensitivity may be initiated as a secondary data transfer mechanism after focus of attention has first started alert related processes. Crowds at lower densities will be more likely to have lower collective power ranges and their biomagnetic signals may be dispersed and not carry far. Relevant factors leading to successful group co-ordination are proposed to be multiple; physical, physical proximity, crowd numbers, environmental conditions but also successfully empathising with others (positive emotional contagion or successfully synchronising), and perception of similarity in others in the presence of shared threat. Negative expressions of group co-ordination are participating in mass violence (negative emotional contagion), failure in harmonisation with a rival group/s and hostile perception of difference in others.

\subsection{Mob Characteristics}

Every crowd is a unique emergent non-linear phenomenon which will never be repeated in exactly the same composition and behaviours; the mood of the crowd is unique to each occasion. Implicit in this logic is that it will therefore produce a biomagnetic field each time with some unique characteristics; every public gathering 
should therefore be planned for as a unique emergent event as it is impossible to predict who will be present each time and in what emotional state.

\subsection{Environmental Factors}

Some variation in interpersonal signal transmission may be caused by geomagnetic factors, it was suggested there were "associations of geomagnetic storms (GMS) with numerous cardiovascular, psychiatric and behavioural outcomes. Various melatonin hypotheses of GMS have suggested that temporal variation in the geomagnetic field (GMF) may be acting as an additional zeitgeber (a temporal synchronizer) for circadian rhythms, with GMS somehow interfering with the hypothesized system. The cryptochrome genes are known primarily as key components of the circadian pacemaker ultimately involved in controlling the expression of the hormone melatonin." Close, proposed "that GMS (geomagnetic fields) lead to disorientation of hormonal systems in animals and humans, thus explaining the effects of GMS on human health and behaviour." [55] [56].

Other work [57]-[62] suggests that there are impacts of geomagnetic environmental fluctuations on behaviour. Environmental factors that may be significant are therefore believed to be multiple, [40], it is suggested that light can pass via the amygdala in the limbic system to send signals to the cerebral cortex. The participation of the amygdala in light-induced alertness implies that "light is provoking and modulating emotions that induce alerting responses" [41] distortion; ambient magnetic fields in the atmosphere constantly fluctuate, local rock formations distort magnetic fields, physical temperature and humidity may also affect signal strength as they impact on the physiology.

\subsection{Locations Facilitating Crowd Formation}

Public spaces, social events where people are assembled in close physical proximity, political meetings, sports events, religious ceremonies and especially emotionally significant events are all likely to raise participants base metabolic rates, emotionally intense experiences are all hypothesised to be significant. There may be some locations where different groups with competing interests are likely to meet with special emotional significance or localised geomagnetic peculiarities, so environmental scans can be considered when conducting experimentation. Some collective events may be time specific, effects may be accentuated in night time when other sensory inputs may be lessened, the unconscious may amplify senses still able to give valid inputs or in noisy environments for the same reason.

\subsection{Role of Similarities in Crowd Formation}

There appears to be some basis for perception of similarity acting as a social glue. It is suspected this may include a genetic imperative to favour those that are more genetically similar to our own genetic makeup.

Socio-political attitudes were observed to be reflective of physiological similarities expressed through the functioning of the individual emotional system, it was found that similarities in political opinions in those who were more reactive on skin conductance measurements and involuntary blink responses (being easier to startle) indicated predominantly conservative social values compared to those with a lesser response, who were of more liberal views [63].

It is not known to what degree this would facilitate or impede crowd formation, but it may possibly give some characteristic political or religious signatures to some crowd's collective metabolic signals which may hypothetically be recognizable by unconscious processes as similar.

\subsection{Sound and Vibration}

Sound contributes to emotional contagion, but as a propagation medium it is not always possible for crowd members to hear simultaneously across a crowd in a way which would induce the same synchronised behavioural responses. It can be hypothesised some unknown self-reinforcing energy wave packet or pulse which maintains its shape travelling at a constant speed (a soliton) may have a similar effect. It can be proposed that vibration acts as an internal aspect of brain function [64] for data transfer, and it has been reflected on the role of vibration in inducing electromagnetic currents in cells, so this may be a contributory mechanism involved in informational transfer. It would have to move through the ground, air or water with minimal distortion and be able to be modelled to behave is a way consistent with known crowd behaviours be considered. Vibration, phero- 
mones and sound may all also contribute to crowd co-ordination, but these are more localised under larger crowd conditions and may operate more variably in crowd reactions, they may also be subject to environmental weather variations. It may be that when transmitted through the ground rather than in an inter-cellular fashion, vibration would transmit data at a slower rate and appears less likely to have emotional content. Information transfer via this means may be evolutionarily useful in indicating an approach from afar rather than being used in immediate survival critical events in proximity to others in humans, but further research may clarify its significance.

Ultrasound technology is certainly known to be capable of providing information in body scans and is used by bats for navigation. There is no indication of an organ capable of this in humans, this sensitivity appears confined to bats who have specifically evolved organs, although it is known that oscillating magnetic fields induce vibrations in cells, see [65], for an overview of vibrational phenomena. Ultrasounds effects are of future interest for exploration as it is not known if ultrasound can interact coherently inside humans with biomagnetism for data transfer [66].

We have a big advantage in that we can ask human participants in crowds and riots what they experienced during these episodes. During communal cognition episodes, accounts revealed that activity involving selfevaluation and reflection was minimised, this focus on external events caused the sense of self to be diminished [67]. It is suspected but not known if situations where verbal communication is impeded leads to accentuation of these hypothesised non-verbal emotional detection mechanisms [68].

Emotional contagion appears to work in conjunction with other forms of data exchange, emotional responses are strong in a region of the brain known as the posterior superior temporal sulcus, a part of the brain that responds to both facial and vocal expressions of emotion and acts in a multi-modal way, processing both sound and vision to generate an inference of where another person may be looking [69] [70].

\subsection{Smell}

Pheromones emitted under certain emotional states (such as experiencing fear) are known to significantly affect mood in others, but may be dispersed by climatic variations such as wind, minimised by clothing, temperature and rain, and while it cannot be discounted as contributory, may not be sufficiently consistent in different environmental situations of disorder to explain the consistent emotional contagion phenomena which appear to take place in a similar fashion under different environmental conditions.

Smell has a vibrational element in that each odour is composed of a molecular chain which vibrates at its own particular frequency according to the exact make-up of the molecular chain [71] [72]. While it is known they can have an effect, it is not known if pheromones in the air collectively interact with ambient vibrational or biophotonic fields to affect emotional sensitivity and would be subject to large fluctuations under different weather conditions as well as clothing.

\section{Crowd Dynamics}

\subsection{Sub Crowds}

Crowds do not appear to be homogenous, localised higher and lower levels of collective co-ordination within a crowd appear to correspond to expression of "sub-crowds" theory [73] [74], within the crowd, friends or families may show more co-ordinations of behaviour with each other than with the rest of the crowd. This more rapid co-ordination may correspond to previously established synchronisations allowing quicker collective action/intent at a lower level of signal input/metabolic activity of some parts of a crowd more readily than others, this would implicate some part of the memory function may be retrieved in synchronisation.

A crowd is in effect made up of a fluctuating collection of sub units, some of which may be in greater states of excitation than others; within a crowd some sub crowds may be in a state of fight or flight whilst other sub units are still unexcited. Some people therefore appear to be more sensitive to emotional contagion and group formation than others, as mentioned, previous synchronisation events may be one factor which influences how prone people are to group participation.

Inhomogeneous crowds or sub crowds, imply that some parts of a crowd may be less conductive of signals than others, and may cause signals to become spiral in pattern as they move through larger crowds, due to some parts of the wave moving quicker than others, experimentation would be of interest in exploring this hypothesis. 


\subsection{Historical Environmental Factors}

The body appears to have the ability to respond to demands put on it [75], and the ease of a initiation of a coordinated violent group reflex may be proportional to the historical severity and frequency of violence in the environment that members have previously experienced. It could be hypothesised that people who have been forced to live in violent and unsupportive environments are epigenetically adapted by such challenging environments [76] [77]. These people may have a base emotional condition which is closer to fight or flight phase transition responses than seen in people growing up in non-violent environments. As their metabolic rate under these circumstances may be higher, so it is argued that the bio magnetic signal that they emit will possibly be more powerful. Their own detection system for bio magnetic emissions is likely to be ramped up as the unconscious monitors the environment for danger more frequently. It may also contain more signatures of stochastic characteristics which are implicit in emotionally exited situations.

\subsection{Previous Interactions}

Other factors which may sensitise to emotional contagion are habits which make synchronisation with others easier; such as experience of previous synchronisations, [78] [79]. This can be argued to be instinctively known even if not understood. Military training emphasises establishment of these routine synchronisations (team work) to make group formation reflexive, smooth and as fast as possible. These repetitions may induce commonalities in thought processes such as systems of belief and political opinions may also affect metabolic patterns in a similar way in different individuals giving a bio magnetic signature in common that the unconscious can detect.

\section{Influences on Attention Focus}

\subsection{Memes, Culture and Metabolism}

The principle of synchronization appears fundamental to crowd formation, as well as with other people, this phenomena regulates signals across the brain within our own mind [80].

Internally strong centres of mental activity may act as focii: synchronisation of oscillation centers capable of obstructing external signals from synchronising with our internal routines; providing a stronger internal focus of attention which may distract us. Repetitive behaviours such as obsessive compulsive disorders appear to be strong internal repetitive cycles which can be difficult to affect by external stimuli. If internal rhythms are overly strong, this may take place to the exclusion of the exterior world, at the extreme, this is what we define as insanity. Perhaps it corresponds with the feeling of being a lonely martyr, the person who is right when everyone else is wrong; this may give strength of character or delusional behaviour; moral whistleblower or deluded fanatic.

Any moral code or system of beliefs can be considered a set of strong internal repeated mental memes (a transmissible set of ideas or concepts), these are refreshed in memory in a repetitive fashion in a similar way as circadian rhythms. If we no longer recall memories (or ideas) frequently, the body appears to assign less calories and proportionally lesser importance to maintaining them and we forget them, facilitating metabolic efficiency. The persistence of memory may be limited by the frequency of recall, so there must logically be a means of determining how frequently the mind has recalled a memory which then influences how much resources are devoted to maintaining that memory.

What has been traditionally termed our strength of personality may be related to the strength of our internal rhythmic patterns against decoherence from influence, by both external environmental patterns and internal signal decay.

\subsection{Failures of Synchronisation and Individual Variation}

Crowds are notorious for being able to absorb initially detached individuals into their own behavioural dynamics [81]. However this does not happen in all cases. There can be many reasons hypothesised for some people in crowd situations being able to resist emotional contagion and entrainment by others. As previously mentioned, normal physiological variation between individuals should logically cause different degrees of perception of others emotional state, (as well as differing levels of interior mental focus distracting from exterior signals). Natural physiological variations implies, some may receive the same signals as others but interpret them differently or fail to interpret them. Cultural factors also play a role in qualifying the intensity of violence where crowd members have a pre-existing internal mental memetic structures (value systems) with certain characteris- 
tics giving them an internalised level of violence past which they do not wish to pass [82].

Different hypotheses can be advanced for participation resistance; they may resist because differences in internal brain structure may screening out others biophotonic patterns as not being similar enough to synchronise with; at an extreme, the traditional "free spirit" may be a person who's subconscious processes do not recognise anyone else as ever being similar enough to activate group cognition with.

Strong internal memetic iterations such as that seen in religious, moral codes, and strong beliefs may provide points of internal mental focus against which external events are unable to gain priority in cognition. These may give strong internal memetic integrity of thought routines [83], which may possibly resist disruptions to their pattern from others biophotonic patterns. There appears to be some linkage with repetitive thought patterns and religion, [84] dopaminergic activation was found to be key in activation of religious experience [85].

Other potential barriers to synchronisation are that some people may have irregular internal mental processes and so synchronisation is sporadically or never completed. Such differences in internal structure may be able to resist very high levels of transmissible environmental metabolic signal. Other internal mental structures resulting from culture and experience may play a role in resisting emotional contagion from those perceived as dissimilar.

Differences in physiology imply signal interpretation may be considerably modified by variations in other ambient factors, research indicated sound, smell, touch and even temperature [86], all contribute to an overall emotional condition, environmental input interacts with internal processes in curious ways; on a cold day we may be more suspicious or emotionally distant than on a hot day due to these subliminal factors. Influences on how open people are to changes in behavioural patterns in a particular crowd situation could be implicit in the natural tendency or crowds to fluctuate and move.

The other obvious argument that could be made for synchronisation failure is that such signals are not perceptible, or continuously perceptible through this medium and synchronisations are due to other data transfer channels. This argument requires further experimentation in light of the unusual physiological characteristics of the body advanced in this review as being of interest as possible data transfer channels.

\subsection{Memetic Signatures in Metabolic Emissions}

Signatures of previous synchronisations which could be recognised unconsciously are unknown but may be established by previous mutual repetitive behaviours; known methods are those induced by religious practises such as daily prayer sessions, regular attendance at political rallies or even regular meditation, all containing periods of calm and emotional excitement which affect metabolism in regular and predictable ways. These may all have a purpose in facilitating co-operation reflexes in group behaviour. There has certainly been great emphasis placed by religions and political groups on repeated attendance and repetitive actions at events and communal repetitive behaviours which may be designed to imprint unconscious reflexes in the subconscious. People who have previously interacted together are known to be more prone to rioting together [87]. While these religious, cultural or politically based circadian type thought processes may have characteristics of giving resistance to the influence of outsiders, in a crowd they may also act in the opposite way to facilitate emotional contagion from insiders. If we are in a crowd of people with which we share culture, religion or political beliefs, these pre-existing similarities in metabolic patterns may make for recognition flags giving easier synchronisation between unconscious minds in a far more rapid effective way in crowd situations. It may be that religious or nationalistic sentiment often evoked by leaders and propagandists in crisis evolved precisely to increase speed of group cohesion in warfare or against environmental shocks from natural disasters. Naturally some organisations may wish to switch off more challenging logical thought processes in adherents in favour of a less reflective emotional cognitive process incapable of rational assessment in the face of a real or manufactured exterior threat.

\subsection{Metabolic Efficiency in Unconscious Assessment}

Inside the body there appear to be multiple internal clocks distributed in organs, each of which set rhythms, which these synchronise over the rest of the body [88].

It is not known if this mechanism is mimicked by different groups of memes having their own internal cycles recording how frequently they are recalled and assigning them a different level of importance according to this. The use of stereotypes may be a way for the body to economise on metabolic activity and time required to threat assess someone unfamiliar to us, trading accuracy in assessment for speed of cognition; surprisingly research [89], found that unconscious decisions were more accurate than reflective decision making. In evolutionary terms, this use of stereotypes would be likely to be favoured as it would provide a quicker instinctive response to 
possibly fatal encounters with strangers. This may not be so well adapted to globalised societies where stereotyping would be more likely to produce false negative danger signals on a daily basis during routine interactions with persons perceived as strangers from a different group with consequent unnecessary stress levels [90].

It is suspected that we associate with those similar to us because we understand them easier, we can risk assess such people with less effort and lower metabolic cost.

\section{Types of Physiological Mechanisms in Emotional Contagion}

\subsection{Possible Evolutionary Sources}

As civilisations evolved from simple hunter/gatherer structures, most risks to personal safety increasingly came from other people rather than animals, a sensitivity to anger and violence would continue to be useful in selfpreservation. It appears unlikely that humans are immune from such evolutionary pressures and this should continue to be expressed in current adaptations to environmental factors (see Optimal Foraging Theory [91]). If this sensory advantage was present in our evolutionary ancestors, there appears to be no logical reason why this would not be retained in current human physiology due to the advantages that such a sense would convey.

Evolution appears to work on a principle of "just good enough" [92], if the method works well enough, it is liable to be retained although there is always a base level of random experimentation/genetic variation, change only comes if the environment itself changes significantly requiring a physiological response.

The Human Genome project found "Similarities between mouse and human genes range from about $70 \%$ to $90 \%$, with an average of $85 \%$ similarity, but a lot of variation from gene to gene "it should not be surprising if these similarities extend to commonalities in mechanisms of how humans and animals scan their environments."

\subsection{Proposed Sensors}

These traits are shared by widely divergent animal physiologies evolved from a cellular level to more complex organisms [93] [94]. In humans, we see in neurones, similar structures to animals, the ability to co-ordinate with each other, especially in circadian rhythms required for overall bodily function co-ordination, [95]. Work on magnetosensitivity of cryptochromes in the retina of birds, [96] [97] shows magnetosensitivity in animals at extremely low power levels, humans also have cryptochromes [98].

Both humans and animals may process these signals in a similar way and share sufficient commonalities in neural structure to operate in a comparable fashion hence the historical rationale for the use of animals in drug testing products intended for human use. These shared structures may also indicate that animals share similar sensations and emotions that humans do, animals certainly appear to have personality traits, go to sleep and, get angry or scared in a similar way to us.

Oxidised tryptophan and oxygen, are known to be magnetically sensitive. Tryptophan is a fundamental part of the human nervous system, also that "a rapid equilibrium between free and bound ligands, changes in the local magnetic field can be coupled chemically to the nervous system" [99] [100].

If the nervous system had the characteristics of "a magnetically sensitive chemical reaction with a ligand product molecule" we should see a fine tuned system which could rapidly make a phase transition from conscious thought to unconscious thought to react to external biomagnetic events. The presence of a combination of paramagnetic proteins, heme and magnetite is significant in nature; there appear to be a wide range of magnetically sensitive tissues shared with humans. It was proposed that magnetite was one method of detecting magnetic fields for orientation, in pigeons (it was also found that blind fish can shoal [101]). Commonality of magneto sensitivity is seen across many species; simple cells interpret magnetic input to change their responses, insects also share swarming behaviours [102], consistent with magneto sensitivity.

Hypothesised signals are of very low power so for a credible detection system in the body to exist it should be extremely sensitive and be triggered more by qualities in the signal which enable it to be magnified by environmental factors/powerful detection structures in the body than by signal strength.

\subsection{Structures Possibly Involved}

Experimental problems with evaluation of emotional modification due to magneto sensitivity were outlined, "whereas receptors for sensory modalities such as vision and olfaction must contact the external environment to detect stimuli, this restriction does not apply to magneto receptors, which might plausibly be located almost 
anywhere in an animal's body. Magneto receptors might be tiny and dispersed throughout a large volume of tissue, or the transduction process might occur as a set of chemical reactions, so that there is not necessarily any obvious organ or structure devoted to magneto reception" [103]. Mechanisms built more around cellular concentrations of magnetically sensitive materials may be more significant than distinct organs, this inference is supported by the parts of the brain suspected to be involved in processing such signals (hippocampus, Noradrenergic Locus Coeruleus, Amygdala; the Habenula, Raphe nucleus and basal ganglia) being similar to those found in animals. Processes involved in these areas are subconscious processes used as are survival mechanisms which influence physical response decisions.

Examination of biophysical research indicates multiple potential detection mechanisms in the body for emotion bearing magnetic waves; paramagnetic proteins; (proteins which become magnetically sensitive when exposed to an external magnetic field) [104], chromatins, neurotransmitters, cryptochromatins in the retina, magnetite in the sinus and heart and blood heme in blood. These structures are both magnetically sensitive and used as part of the brain and nervous system in thinking [105]. Sensitivity to exterior magnetic fields may also possibly increase and diminish at different times according to the various internal circadian rhythms of the body. As previously mentioned [106], it has been proposed that magneto receptive transduction in the nervous system as evolving historically well before human physiology, it was stated that” Biogenic magnetite in the human brain may account for high-field saturation effects observed in the T1 and T2 values of magnetic resonance imaging and, perhaps, for a variety of biological effects of low-frequency magnetic fields" [107].

"The occurrence of Magnetosensory Evoked Potentials in response to a weak magnetic field suggested the existence of a human magnetic sense. In distinction to the evoked potentials ordinarily studied, MEPs were nonlinearly related to the stimulus as evidenced by the need to employ a nonlinear method to detect the responses." [108], see also [109]-[110].

It was proposed the ophthalmic branch of the trigeminal nerve was sensitive to small magnetic fluctuations, [111], citing older work indicating a diffused magnetic remanence. Weaker signals are argued to be detectable by paramagnetic proteins, heme and magnetite in the body; "recent research has established that the noise in biological systems can play a constructive role in the detection of weak periodic signals via a mechanism known as stochastic resonance. In essence, stochastic resonance is a nonlinear cooperative effect in which a weak, normally sub-threshold periodic (coherent) stimulus entrains ambient noise, resulting in the periodic signal becoming greatly enhanced and is able to produce large scale effects." [112].

This was supported by findings that, "results show that human CRY2 has the molecular capability to function as a light-sensitive magnetosensor and reopen an area of sensory biology that is ready for further exploration in humans" [113], concerning human gene sensitivity independent of light in the retina. It can be argued that other people in the crowd are (via their own biomagnetic signatures) the ambient noise which is being entrained by some people who are producing stronger biomagnetic signals than others.

\subsection{The Role of Skin}

Biomagnetic signals would have to traverse the space between people, the skin would be a barrier that would be crossed by these signals in order to be detectable, experiments found physiological changes in the body in response to external magnetic activity [114].

Skin possesses unique characteristics; transmission of internal metabolic activity states are known to be transmitted to the skin surface [115], this is how lie detector machines work. It is hypothesised the skin may detect external magnetic signals via the electric charge of the skin, possibly inducing plasmonic fields guiding signals across the surface of the skin to receptors. It is argued that sweat in skin pores may magnify environmental signals [116] [117], theoretically boosting detection of external biophotonic and biomagnetic patterns although others [118], disagreed on the role of skin pores as detectors. Crowds experiencing higher temperatures and humidity appear to be more volatile, it may be that the emotion bearing signals they receive are stronger due to this amplification effect, (see [119]) although elevated temperatures also add on their own to emotional volatility.

Riots are more frequent in summer and of a greater intensity, crowd participants would sweat more in summer and have moisture capable of amplifying signals present in skin pores to a greater extent. Increased production of pheromones in hotter climatic conditions would also logically amplify this effect. This potentially increased sensitivity to magnetism caused by ambient factors is suspected to be used by magnetically sensitive proteins in the body [120], as well as previously mentioned concentrations in the brain [121]. 
This effect may possibly also involve Merkel cells in the skin, [122], which communicate in a bi directional manner between the bodies interior and the environment. If the body may be structured to also detect significant patterns in weaker fields from persons nearby, detection of anger and fear in others via the unconscious would be argued to be most significant in survival and it can be suggested as being involved in initiating collective or mob behaviour when it surpasses a certain strength. It is not known if Bonghan vessels, (see [123]-[125]) are involved in signal detection and transmission, the system appears to circulate granules loaded with DNA which is known to be paramagnetic, [126] interestingly they are known to be present in bovine hearts and so may also be present in the human heart.

Detection by the body of environmentally significant energy emissions may function via sensitivity to the "butterfly effect" type characteristics of those signals rather than the power of the signal, [127]-[129], what appears to be significant is the characteristics of the waveform rather than the power and intensity. It was found "Recent studies of the minute morphology of the skin by optical coherence tomography showed that the sweat ducts in human skin are helically shaped tubes, filled with a conductive aqueous solution. A computer simulation study of these structures in millimeter and submillimeter wave bands show that the human skin functions as an array of low-Q helical antennas. Experimental evidence is presented that the spectral response in the sub-Terahertz region is governed by the level of activity of the perspiration system. It is also correlated to physiological stress as manifested by the pulse rate and the systolic blood pressure." [130], Others, [131] felt "multiple interference effects from the skin layers play the major role in determining the skin electromagnetic characteristics in the millimeter and terahertz regions without the need for the assumption of the sweat ducts acting as low- $Q$ helical antennae" so debate on these mechanisms appears ongoing.

\subsection{Significance of Individual Variations in Signal Transfer}

Other variables are typical individual physical differences in body structure such as some people run fast, other run slow, some have a strong signal, some will be weaker; signal strength will be likely to go up and down with physical health, age and emotional state, it was found there were substantial variations in individuals biomagnetic emissions, [132] [133]. The conformation of the skin pores is unique to each individual, efficiency of mechanisms of reception may be dependent on the conformation in each individual of their miniscule ridges of skin. As our fingerprints are unique, the ability of each person to capture biomagnetic signals and photons therefore depends on their individual physiological factors.

While we can argue every person may be hypothetically able to detect biomagnetism, when we design experimentation to emotional contagion, they should control for individual differences which may be greater than expected. Human physiology has significant variations, (see [134]-[136] which would be hypothesised to add considerably to unpredictability of responses in crowd members to stimuli. Other individualistic variables are the degree of historic previous traumatic experience which has influenced mental structures through induced epigenetic evolutionary responses to environmental factors.

\subsection{Epigenetic Plasticity}

Body plasticity implies the body responds to the environmental demands placed on it by continually modifying itself to better match environmental changes, [137]-[139].

Certain types of emotion in response to environmental changes may form fundamental metabolic patterns modifying the hearts patterns and therefore reflexes into eventually being structurally different if sufficiently prolonged, if we are consistently in violent environments, we eventually become used to it. As the heart has particularly strong internal rhythms linked to personality implicit in its routine functioning, it is suspected (but not known) it hat heart physiology may be to some degree be modified by personality patterns. It is not known if repeated exposure to certain types of exterior signal would induce persistent changes in the hearts own metabolic operations and internal rhythms.

If this hypothesis is valid, biomagnetic senses would also be subject to environmental re-modelling according to survival requirements, much as all other senses are. It does not take long for humans to experience heritable physiological modification in evolutionary terms, Tibetans were believed to have migrated from lowlands to the Tibetan Pleateau only 20,000 years ago but appear to have developed lungs which are far more efficient at extracting oxygen at high altitudes, [140] [141] illustrating the high degree of plasticity of the human physiology.

From this perspective, persons brought up in violent environments, especially where the violent nature of the 
environment has persisted over generations, should logically have physiological modifications to their environmental sensing. The amount of stimuli required for physiologically significant adaptation may be small [142] but may be more significant if stimuli are consistently repeated. This work connected neuronal synchronisation to internal metabolic response to an alert, pre-existing pre-stressors imply small events may provoke significantly larger changes in behaviour than expected from such seemingly minor stimuli and cause quicker and stronger group formation. Expected results would include greater physiological sensitivity to biomagnetism, and possible diminution in life expectancy due to a higher base level of metabolic activity creating greater physiological wear and tear.

It may be that in persistently violent environments (eg the Hundred years war in Europe), theoretically epigenetic processes [143], may also invoke modifications over generations which cause a decrease in energy and/or stimulation required for activation of phase transitions in switching human behaviour. Increased base levels of alertness linked to transition to emergency/group behaviours would be seen in proportion to the historical level of environmental violence that ancestors as well as the current population experienced.

Those predisposed to group violence may personally have high base levels of aggressive emotion as they have already been synchronised to violent people in their environment, [144], they now repeat those patterns in their personal emotional behaviours by habit, repeated domestic violence, intergroup conflicts such as frequents fights between gangs in an area, civil war, insurgencies and interstate wars may all instil such responses.

The accumulated genetic experiences of several generations' experiences may be expressed in this way in a similar fashion to the genetic markers left by experience of starvation [145], perhaps by evolutionary modification of the genome by RNA and prions similar to that found in yeast [146]. These modifications may reverse themselves progressively if the environment becomes peaceful as violence related adaptations may be expensive from a calorific expenditure perspective.

\subsection{Directional Sensitivity}

There would be a significant survival advantage in having a directional sense for danger signals. It appears likely that significant environmental input is processed in regions of the brain linked to the raphe nuclei which provides feedback to the suprachiasmatic nuclei in the brain stem area implicated in vigilance alertness and circadian rhythms, this region appears also to be present in animals such as rats.

Several indications of the significance of magnetically sensitive materials in operation of the nervous system are that malfunctions of iron concentrations in brain iron pathways were suspected to be linked to Parkinson's disease, [147], implying that compounds with magnetically sensitive iron content are fundamental to operation of the nervous system, (see also [148]) for bloods role in cognition. Our survival has historically depended on rapid detection and reaction to hostility and danger nearby, having a directionally sensitive detection system for sensing hostility would carry a considerable evolutionary advantage and be likely to be passed on to descendants, [149]-[151].

It was found that blood in the body is sensitive to a magnetic field coming from a particular direction, [152] [153], Iron in heme appears to have anisotropic (directionally sensitive) qualities at room temperature, [154], paramagnetic neurotransmitters are concentrated in the mesencephalon, (used by the body for reward and addiction) [155].

\subsection{Proposed Signal Transmitters}

For Magnetosensitivity to be possible, as well as detecting signals, the body must also have a transmission mechanism to project emotional content, as well as the heart appearing to be sensitive to external electromagnetic fields, it also produces the strongest electromagnetic field from the body of any organ [156] [157]. While weaker than MRI fields, magnetic fields from the heart are detectable at some distance from the body and may be more detectable than their power would suggest as their variability may contain patterns with a stochastic resonance quality capable of amplifying itself through absorption of environmental "noise", as it is intimately linked with metabolism, therefore it is suggested that the heart is the principle emitter of biomagnetic signals.

It was established that patterns of the heart appear to carry patterns of metabolic activity corresponding to personality and mood [158], persons who naturally have a more rapid heart rate from birth may be more likely to have active metabolisms rather than lethargic ones and this would be reflected in personality differences, giving a fiery or energetic personality. If we are distressed or ill, our body reflects this in changes in emitted bio- 
photonic and biomagnetic patterns, emitted patterns contains information corresponding to the nature of that distress or illness [159] [160].

Heart research has found some curious properties of the heart, "Signal averaging techniques are used to show that when two individuals touch or are in proximity, one's electrocardiogram (ECG) signal is registered in the other person's electroencephalogram (EEG). While the transmission of the signal is strongest when people are in contact, the effect is still detectable when subjects are in proximity without contact." [161].

Others [162] [163], mentioned sensitivity of the heart to geomagnetic fields. Understanding exterior magnetic signals possible effects on personality requires demonstration of a linkage of exposure to particular patterns to changes in the recipient's metabolic patterns and consequently expressed changes in emotional state.

Statistical differences were found in transplant subjects personalities [164], following heart transplant surgery, subsequent to which patients appeared to reflect aspects of donors personalities. This surgical procedure can be said to internalise in a stronger way what would be receivable from an external signal emitted by someone else's heart nearby. This appears to influence the heart recipients personality with elements of the donors personality. The observed effect in transplants would be extreme as the recipients own heart is no longer there and would not be able to modulate such an effect from the donor's metabolic patterns with its own rhythms.

\subsection{Magnetite}

Reception and projection of mood signals to and from others may be linked to high concentrations of magnetically sensitive magnetite found in heart tissue [165], possibly significant for biomagnetic signal detection and transmission, this large bioenergetic field generated by the heart appears to be implicated in synchronisation of biorhythms.

As an outline, there are two possible reception mechanisms; "Thus magnetoreception is connected to chemoreception in the first case and to mechanoreception in the second case. The two hypotheses are equally plausible at this stage of experimental evidence and it is due to the scope of the conference that this review is mainly focussed on the magnetite hypothesis. Relying on completely different physical principles, the two hypotheses do not mutually exclude each other. On the contrary, there is good experimental evidence that both types of magnetoreceptor principles may be realized, even in one and the same animal" [166] [167].

\subsection{Signal Strength}

As previously discussed while fear appears significant, other emotions also appear significant; anger produces not only the greatest physiological changes in metabolism but also the largest bio-field signature detectable outside the body. We can infer different emotions produce different physiological responses [168]. This research did not include exited groups of people under riot conditions where signals would be likely to be boosted due to amplification interaction effect produced by two clashing groups perceiving each other as threatening. Variables in signal strength are argued to include how close to each other are we, how many people are nearby [169] [170], what physical characteristics they have and what emotional condition are they in as this all influences the characteristics of their bio magnetic field.

If we lived with someone miserable, would we internalise and absorb a miserable persons metabolic signals into our own metabolic patterns? There is certainly anecdotal evidence of people with happy personalities who can "light up a room" when they enter and avoidance of miserable people is a well known phenomenon.

Future experimentation may clarify if accumulated historic metabolic patterns induced by emotional iterations may be transferring historic emotion related patterns from donors to those of recipients. It has been noted that there are similar cells around the heart as found in the brain linked to cognition [171] the role of neurons and astrocytes in intercellular magnetic communication is still being explored [172].

\subsection{Arguments against Sensitivity}

Arguments against biomagnetic sensitivity logically would centre around the body's ability to do three things; refuting that the body emits coherent meaningful emotional information, that it can transmit this coherently, and that it can be consistently received and interpreted by others. Criticisms have been made that the body is insufficiently sensitive to detect exterior magnetic fields. A review, of magneto reception by Johnson et al. (2005) stated "humans either lack magnetoreception or are not consciously aware of it".

It can also be argued that rather than bio magnetic sensitivity transferring data, facial micro expressions per- 
ceived in others, such as reported in two works [173] [174], could be argued to cause the same effects; increased tension, emotional contagion and crowd formation. Facial response to difference are indeed understood independent of culture, such as dislike, anger and disgust [175] [176].

While this argument is valid for interpersonal interactions or on small scale interactions, this argument for facial gestures alone does not seem sufficient for rapid emotional changes in large groups which may be in conditions of restricted visibility (such as at night) with high ambient noise. It would require experimentation, but initially appears more likely that facial data inputs act in conjunction with other senses to create a stream of consciousness used by the brain, rather than being exclusively responsible for crowd formation.

The difficulty in detecting low power emissions can be argued to invalidate biomagnetic transmission, Biomagnetic signals from other people would be initially transmitted at very low levels of power, (nano/pico tesla), so would logically require an amplifier to function. However the body is capable of detecting sub threshold environmental events due the extraordinary sensitivity both of the optical nerve, which allows a single photon landing on the retina to be detected [177], and of the nervous system in general. The nervous system was argued to absorb small levels of power per synapse, less than 10 - 13 watts. [178], and low powered magnetic fields were argued to interact with proteins at very low power levels [179].

Detection by the body of environmentally significant energy emissions may function via sensitivity to the stochastic characteristics of those signals rather than the power of the signal [180]. Significantly, even these picotesla level fluctuations did appear to be detectable by the body [181], however the degree of perceptibility of information transfer via environmental fields appears to be subject to large fluctuations linked to a large number of internal and external emergent phenomena which may amplify or degrade signals unpredictably. Individual characteristics of internal processes adds additional variables in attempting to decode the changes in the outside world [182] [183].

Sight has previously been advanced as being entirely capable of producing complex flocking behaviours, [184], and it certainly plays a strong role in initiating group behaviours through focussed attention, however larger human crowds cannot clearly see much beyond their immediate neighbours and yet share changes of emotional experience which propagate "like molecules diffusing and reacting in chemical mixtures" [185]. Such an effect would require a transmission media which can propagate through tissue rather than relying on line of sight alone. As this effect has not previously been looked for there is a need for further observations of real riot situations with this in mind.

Arguments for biomagnetic data transfer are subject to the caveats of uniqueness, extreme fluctuations and variations of every part of the emergent system we consider as a crowd, experimentally the most that may be achievable are identifications of similarities of process rather than replicable results, but new brain scanning technologies may be able to assist in identifying synchronisations as they evolve to allow real time field observations.

\section{Signatures of Organic Life}

\subsection{Detection of Life}

If low power signals with stochastic qualities are significant, such signals would have properties of matter which are present in living systems but not in inorganic matter. Biophotons were proposed to be uniquely present in living systems.

An interesting work [186], proposed that a biophoton was a photon in a squeezed state which was the signature of life, the photonic field being oval rather than round as a by-product of metabolic activity. Logically the accompanying magnetic wave would also be warped with specific characteristics which can carry data. A unique property of organic life capable of transferring information, appears to be spontaneous photon signals. This ability to store and replicate data coherently may be fundamental to life.

A secondary characteristic of a squeezed state photon is that it can also improve reception of weak signals. Biophotons differ in that they are able to maintain quantum coherence for longer periods, this is significant in consideration of these photons having an informational content, and is also ideal for any neural system seeking to establish and retain memories, communicate and operate circadian rhythms [187] [188], it can be proposed that a low energy mode of quantum entanglement in organic chemistry is typically found in living tissues, this appears to be possible with multiple particles [189].

Stochasticity and coherence of signal may be the signature the body is sensitised to and looking for, certainly 
only living systems have this characteristic. Perception of incoming photons in the squeezed state may be the trigger for the neuronal system to focus attention on living organisms in the vicinity. The accompanying magnetic wave which moves with photons may have different characteristics if the photons are in a squeezed state.

\subsection{Calorific Control Mechanisms}

There may be power laws which operate in crowd interaction in a similar way to other biological self-organising systems, it is not uncommon to see many parts of a crowd in a demonstration only heckling law enforcement or simply watching with a far smaller portion of the crowd actually taking part in violence, this would correspond to lower levels of emotional arousal and therefore lower levels of emotional contagion.

Higher levels of emotional arousal and metabolic activation should see co-ordination in sub units begin to spread, proportionally increasing co-ordination towards properties of a Bose-Einstein condensate whereby any change to one part of the system propagates instantaneously to all other parts of the system.

\subsection{How Effect May Be Switched off}

While it has been possible to outline a hypothesis for a mechanism of emotional contagion, if it exists there should also be a suppressive mechanism to prevent persistent excessive alerts, so consideration should be given to what would be the operational parameters of such a system.

There appears to be a physical proximity effect [190], found that physical separation of people experiencing hysteria diminished the transmissibility of emotion.

Diminished threat (increasing physical separation) may activate natural mechanisms in the brain which register challenges successfully overcome through the absence of stressors in proximity. Perhaps the presence of others biophotonic emissions in the area induces increases gamma and theta waves in the brain in response to emotion related stimuli and decreases alpha waves which organise the brains "to do list". Alpha wave controls attention to visual signals and couples with gamma waves to organise brain activity, it helps to damp irrelevant brain area's for a certain task and is more present in mindful states [191]-[193]. The body would need to strike a balance between the metabolic cost of increased sensitivity and the benefits of detection of danger.

The body would need to be in an ongoing process of striking a balance between the metabolic costs of increased sensitivity against benefits of detection of danger. If the nervous system was constantly paramagnetically activated, the body would use too much energy and suffer too much wear through increased heart rate. The body may switch this system off when it becomes exhausted. It would appear more likely that there would be a base level of environmental input above which such a mechanism would activate and this would be subject to both genetic variation and epigenetic environmental factors.

\section{Possible Nonlinear Dynamics}

\subsection{Crowds as a Dynamic Process}

The operations of dynamic networks such as those found in a crowd would be similar to that of systems whose behaviour tends towards that of complete transmissibility, but which never completely achieve this due to their dynamism of structure. It may be possible to express an equation quantifying of the relevant factors in order to get an approximate a degree of influence ability.

A combination of environmental dynamics, individual character and physical nonlinear dynamic processes are suggested as being responsible for both crowd behaviours and evolution of behaviours in social, political and religious movements.

Research, emphasised the dynamic nature of assemblies, in that during public order events demonstrators and police's mood both changes as a result of mutual interaction [194]. An element of raised emotional engagement amongst participants appears to be required for crowd formation, a very hostile crowd should cohere far quicker than an assembly of debaters at a philosophy seminar. Cohesion takes place through unconscious cognition processes as discussed previously and would be hypothesised to increase the power output of participants biomagnetic resonations as crowd members become more angry or excited, creating a dynamic positive feedback loop and therefore both transmissibility in senders and detectability in recipients.

Observing significant behavioural differences in crowd situations are a means by the subconscious of initiating and engaging both emotion and reflexive reaction, giving it priority over logical thinking. It also increased 
sociality, facilitating synchronisation with others [195].

\subsection{Oscillation and Synchronisation}

It is known that synchronisations of behaviour increase between people who get on socially, we unconsciously mimic those we like, it was suggested "separation from attachment figures is a greater stressor than physical danger", and we form groups with people we like [196]. Teams, and friends are simply people who succeed in synchronizing [197]. Synchrony and oscillation appear to be fundamental to brain function [198]. Data exchanges between crowd members are products of their brain function and would logically function in a similar way. When we consider how synchronisation works in individuals and groups, the closest match of a comparable systems appears to be a mode of individuals behaving as coupled oscillators in a bi-stable system as people alternate between the conscious thinking and unconscious thinking state.

Initiation of synchrony between crowd members may operate through a stepped process of focused attention inducing increasing levels of paramagnetism in proteins, oxygen, heme, and neuronal hormone communicators such as tryptophan, all of which are involved in the thought processes. This can be considered to be nonlinear emergent processes.

Biomagnetic emotional contagion signals appears to propagate between crowd members by biomagnetic resonance being amplified by stochastic resonance using ambient noise; [199] it was proposed that stochastic resonance could amplify communication in neural networks "Because the electric field interacts with neurons even at magnitudes insufficient to trigger action potentials, it provides a means to introduce a sub-threshold signal into an entire network of neurons to probe for Stochastic Resonation” [200].

We can attempt to quantify variables for modelling purposes, inputs into possible paramagnetic activation in the nervous system appears to be both multiple and proportional to a wide range of factors.

\subsection{Nature of Emergent Relationships between Crowd Participants}

An initial consideration of processes affecting crowd mood yielded a substantial number of processes which can be hypothesized to influence emotional states in groups.

- Physiological characteristics of crowd participants; are they starving, drunk, drugged, angry, happy; to what degree are they starving, drunk, drugged, angry, happy?

- Frequency of previous relationships between crowd participants.

- Degree of emotional arousal of crowd members.

- Interactions with opposing groups.

- Number of persons present.

- Number of persons in group or groups opposing crowd members.

- Number and nature of sub divisions in the crowd in opposing groups.

- Physical proximity.

- Environmental conditions.

- Emergent qualities of the space between them, [201].

- The emergent nature of data contained within crowd members and stochastic resonance of the data.

- Characteristics of opposing groups in physical proximity.

\subsection{Stochastic Processes in Crowd Behaviour}

A hypothesis of Biomagnetic based emotional contagion can be inferred to work by the anger signal switches on the unconscious fight or flight response in those nearby, who may then also display aggression, increasing the ambient signals power in the vicinity.

This would induce a stochastic process like the butterfly effect as the anger signal is detected by others, increasing anxiety in those detecting the signal and activating both an increased metabolic rate and projection of their own biomagnetic fields. The initial signal, if it possesses stochastic qualities, is argued to gain power from others in the crowd, it is known that stochastic processes are fundamental to the operation of the mind [202].

As crowd members became physically exhausted, they would switch back to lower metabolic rates losing magnetic sensitivity and be functioning using individual logical cognition. They no longer would be able to act as transmission nodes in signal propagation through the crowd/network. 


\subsection{Oscillatory Phenomena in Data Exchanges in Crowd Members}

The significance of oscillatory exchanges of information as a methodology of data transfer in crowds may have implications as to the mechanics of leadership. A possible mechanism for understanding how this may function is that the ability to lead is expressed in patterns of data in a leader's biomagnetic signal being contagious and spreading to followers so that follower's patterns become more similar to the leaders than visa versa. These iterative oscillations of data between people may function in a similar way to that of centres of gravity in planetary orbits. If we have two planets of equal weight rotating around each other the point in the middle will be the barycentre and both people will be in an equal relationship; emotional states could be mutually symbiotic, mutually hostile/fearful or indifferent but still equal.

Persons with "stronger" personalities we could consider to be people with more stochastic data patterns. They would be the equivalent of a larger planet drawing a smaller planet into its orbit.

Peoples interactions with each other's each other's biomagnetic resonation can be considered as exerting a force on each other (the capacity to entrain someone else's emotional patterns to that of your own) like the gravitational force that small or larger planets exert on each other, the stochastic resonation qualities of some peoples emotional resonation/personality will "weigh" more than others.

The diagram below is an attempt to illustrate the possible characteristics and consequences of wave based repetitive oscillations of data exchange. Certain people may emit more "weighty" emissions than others, and have more leadership-the ability to pull others into your orbit in a similar fashion to gravity.

The diagram may not literally describe energy field interactions between crowd members but is used to illustrate the deforming effect of a stronger personality on a group. MRi scanning of dynamic crowds in action are suggested as hypothetical experimental methodology to clarify possible interactions.

\section{Barycentric Model}

Model showing hypothesized coupled wave oscillation patterns of data bearing biomagnetic waves (Figure 1). Exchanges of data between two persons are shown as an evolving process of coupled oscillations of electromagnetic waves. If synchronization between the two parties occurs, the characteristics of this relationship can be understood by where the orbital point or barycenter is established after an initial period of entrainment between the parties, the more influential party will be hypothesized to be in closer proximity to or containing, the barycenter, apart from a charitable relationship implying a conscious effort to move the barycenter on the part of the donor. Multiparty systems will naturally require more complex modeling.

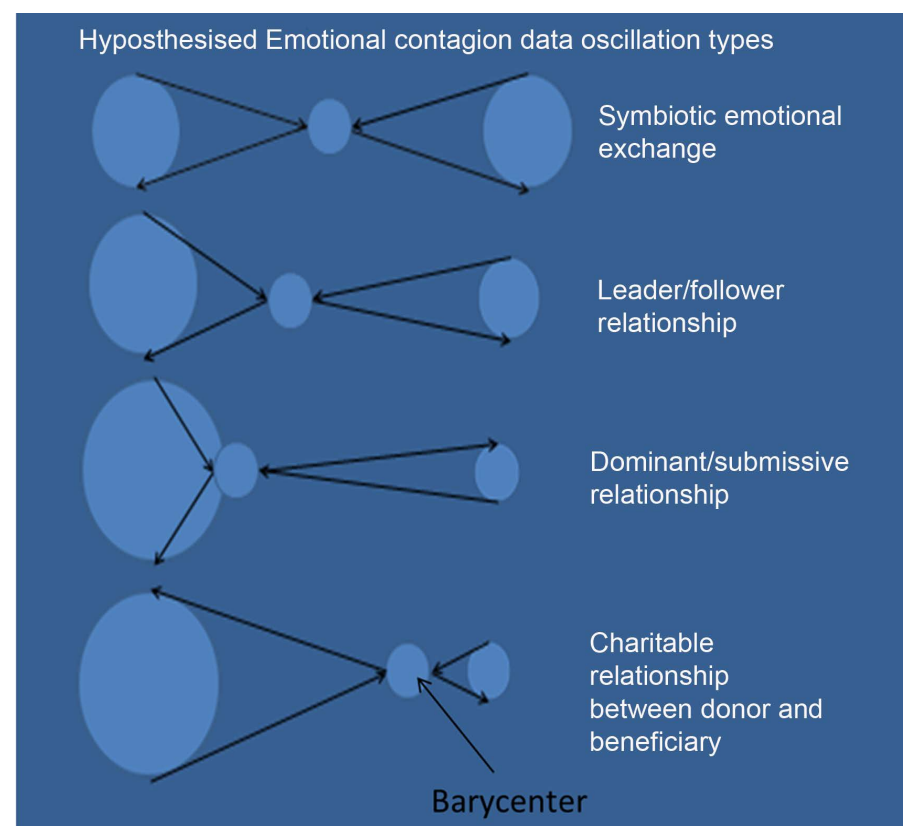

Figure 1. Barycentric entrainment model of interpersonal data exchange. 


\subsection{Possible Entrained Relationship Types}

These diagrams illustrate how we can understand the nature of individual and group entrainment by using a gravity analogy. The hypothesis situates the symbolic centre point closest to the person who has the greatest stochastic resonance in the interpersonal interaction and therefore the greatest ability to influence others through their own emotional patterns.

Some people may synchronise their emotional fields very quickly to others, those who are easily led. There are also evolutionary advantages in being open to others leadership, if we fail to synchronise with others, we may be shut out of the group; from a survival point of view not a good place to be. There can also be disadvantages in leadership, ability to get others to synchronise with your own signals may provide some advantages but also exposes you to risk of challenges from others seeking to lead which can lead to physical injury or death so there is a natural balance between the advantages of leading and following.

We see similar behaviours in animals so we may be using a shared mechanism inherited from more primitive ancestors. This would indicate that the site of this detection mechanism to be more likely to be situated in more primitive centres of the brain around the spinal column rather than more evolutionarily recent frontal cortex regions of the brain.

There can be five types of relationship hypothesised, charitable, symbiotic, Leader/follower, dominant/submissive and the non-initiated or failed relationship which can be understood as indifferent. In work on the correspondence between electro dermal skin responses between people, it was mentioned "The driving force of one oscillator on the other often involves increasing the speed of oscillation" [203], it may be that the ability of one person's internal rhythms to regulate the speed of feedback loops between people may be a possible determinant of the ability to entrain, regulation of the speed of data exchange may be key.

The same work also mentioned higher physiological arousal linkage between people engaged in hostile conversation, this may be a signature of a type of biomagnetic struggle to entrain each other's signals to establish dominance.

The Charitable relationship diagram at the bottom is that of someone who may possess more leadership qualities but is willing to voluntarily move the centre of the emotional relationship to the weaker party to take their feelings into account, what we may see in a parent/child relationship for example where the parent can enforce their will but only at the cost of emotional damage to the other party.

This exchange of information naturally becomes a more complex in a crowd where there are multiple centres of emotional resonation. Some people may have extraordinary abilities to entrain others for good or ill similar to planets caught in orbit around a sun.

A symbiotic relationship would have a symbolic barycenter equidistant between two people meaning they affect each other equally. This can be used to understand relationships; a considerate person would move this point to an equidistant location even if the other person had a weaker personality precisely because they have interior mental structures capable of influencing their own emotional emissions, a bully would move the point closer to him or herself because he or she hasn't or they are fluctuating.

\subsection{Leader/Follower}

A leader would have a barycenter closer to him than the follower so he exerts an influence/entrainment effect on the follower larger than the follower exerts on him or her. People who are strong emitters of emotional signals can be said to be acting as coupled oscillators synchronising the more sensitive to their own emotional condition, this appears to be through the speed of mutual data exchange being matched more to the dominant parties internal rhythms of data oscillation than the followers.

\subsection{Dominant/Submissive}

A predatory relationship would have a barycentre symbolically within the predator's physical body implying the follower has little will of his/her own and is mostly being entrained rather than a two way influence. This is the traditional autocratic leadership model used in totalitarian states or traditional criminal organisations, this type of relationship may also be exerted by smaller groups at the top of an autocratic hierarchy onto wider groups of victims. 


\subsection{Larger Scale Group Relationship Dynamics}

As previously discussed, phase transition from individual to crowd behaviours may involve the nervous system of crowd participants hypothesised to become paramagnetically excited, this seems to initiate what traditionally has been considered the "collective mind" or mob mentality, this appears to be affecting others emotional condition by crowd participants contributing to a dynamic feedback loop. This open communication state may be similar to a network where communication nodes are now in an open state, either partially or fully, enabling multiple communications to take place.

A crowd can be comparable to the image above in that there can be said to be multiple centres of gravity exerting force on each other through emotional contagion, these forces can be understood as emotional data flows. There may be multiple centres of entrainment in a crowd of similar strength, or sources of emotional data flows, these can be a singular large centre of entrainment, multiple centres and/or all sorts of combinations involving fluctuations and alternating centres of emotional dominance. We can understand how this may function in real time situations if we had a senior officer in charge of strategy in a demonstration being knocked unconscious by a flying missile or an agitator being arrested and taken away in a Police van, removing their signal from the network. There are a lot of different evolutions which a crowd as a system experiences continually; we can see these expressed in real time situations which can change data flows.

While this model has not yet been tested, it can only be said to have value as a metaphor for how personalities may entrain others.

\section{Quantum Effects}

\subsection{Other Factors}

The problem with modelling crowds from an emotional contagion perspective is that initial focus of attention may be an initially quantum process with a secondary stochastic process leading to the phase transition to collective behaviour. If we consider a possible data transfer via magnetic wave, there is always an accompanying photon with it which can also carry data but is also potentially subject to quantum entanglement, photon and wave are inseparable.

Crowds have been modelled using many different methods, data transfer in crowds or larger social groups may be harder due to a quantum element of information transfer in addition to normal phase transition type behaviours. It may be possible to scale up methodologies used to understand internal brain oscillations between different parts of the brain if similarities can be demonstrated between brain function and how individuals handle data transfers in a crowd operating as network nodes, if so, stochastic differential equations and dynamic causal modelling may be useful, [204] [205].

It was mentioned in a paper [206] that there was significance of microscopically strong and fluctuating internal magnetic fields produced largely by paramagnetic oxygen in brain function. This was able to produce stochastic resonance to synchronize dynamics to the neural firings. What was also interesting was their mention that quantum coherence may exist although they did not consider it a prerequisite for their hypothesis, quantum coherence effects may tie in with the initial focus of attention effect noted between participants in crowd formation. This effect was proposed in biological systems [207]-[210].

A crowd comprises synchronisation processes with multiple centres of attraction (other crowd members within the group) as well as opposing groups such as Police.

It was described in a work that attractor switching in biological multi-stable systems describing neural populations with excitatory and inhibitory connections [211]. Some parts of a crowd may act in an inhibitory way, being less prone to emotional excitement while others are more prone, going back to the sub-crowds theory. It may be possible to use models of internal brain function systems to extrapolate to crowd member's biomagnetic signals transferring between crowd participants who are acting in a similar way.

Stuart Hameroff and Richard Penrose hypothesised how quantum entanglement may take place at room temperature in biological organisms, proposing it takes place in cytoskeletal microtubules within the brain's neurons [212]-[213]. This may implicate information transfer via quantum tunnelling effects using a dimension or dimensions with Bose-Einstien condensate properties as proposed by David Bohm [214], but this is a particularly knotty problem for quantum physicists who appear to be still debating the true nature of multidimensional space without a conclusive understanding of the true nature of space time that satisfies everyone (or even most )work- 
ing in the field. A vibrational sum of all contributing environmental influences transmitted into the consciousness (including quantum data) may be a possible mode of operation , this would process multiple sources of input which would then be integrated together [215] and co-ordinated in photon pulses "spin energies can accommodate the interactions between protons, electrons, and photons and the action potentials associated with intention, consciousness, and entanglement" [216]. A type of cellular vibration/solitonic effect was believed to be induced during the interaction of magnetic fields with cellular structures, [217]-[219]. It may be possible but not known if this is involved in emotional contagion , such data transfers could combine optical, biomagnetic, soliton/vibrational and quantum channels to form a stream of consciousness for decision making.

There may be some unknown underlying laws which can be used to understand these phenomena, the curvature of spacetime is also oscillating [220]. There may be some fundamental law of nature at work. Oscillation in time recurs constantly in nature and we see this implicit in matter moving in orbits from atomic level up to planets and galaxies.

\subsection{Experimental Problems with Crowd Behaviour}

While previously cited experimental work can be interpreted as circumstantially supporting a hypothesis of emotion affecting bio energetic emissions [219], understanding is needed of what a mechanism would need to do to function so that all or most people in the vicinity interpret emissions in a similar fashion. Subjects of experiments should possess sufficient similarities in both their physiologies and unconscious minds responses in order to provide unambiguous results when exposed to similar external stimuli, although this will pose difficulties in evaluating similarities in both.

Where interpretation takes place in subconscious thought processes it becomes much harder to set up both the subject group and a control group as the individuality of each person's life experiences gives them the possibility of reacting differently to similar input. Scientifically there are experimental problems to overcome in several aspects, magnetic resonance scanning technology is still in its infancy, miniaturised scanners capable of being portable to capture real time human interactions in crowd situations in the field are necessary.

Other difficulties emerge in replication of results in that people and the environment they live in are both dynamic emergent systems and the effect of uniqueness of time and place. Different people would be likely to have variations in not only ability to detect and transmit biomagnetic resonations but also have differences in interpretation of inputs.

In addition, it is of experimental interest as to what effects age, gender, individual physiology, physical fitness and normal circadian rhythms have on whether the body has sensitivity to and transmissibility of biophotonic information and what is environmental factors significance in emotional contagion. While this review may suggest directions, it is not yet verified how or why emotional contagion works, it is hoped that the areas covered by this article are of sufficient interest to justify further discussion.

Experimental attempts to reproduce emotional contagion effects seen in riots in a laboratory setting are problematic. Some differences in experimental results may be linked to the nature of mechanically generated fields differing from biological fields, the body would logically listen for signatures containing biological activity rather than simpler mechanical signals. These mechanical magnetic signals may not carry signals that the body has adapted to listen for through evolution.

Everyone reading this work is likely to have had experiences of meeting or interacting with some people we can't get on with or synchronise with, we may sense they are indifferent or they mean us harm. Some people have an advantage if they can sense this despite the emotional masks some other people use to conceal malicious intent. We can argue we have an evolutionary advantage if our "sixth sense" feels in others metabolic resonations, such as emotional indifference or readiness to commit violence against us. Anecdotal accounts of feeling of the bad vibe when we enter a room, [220] may be explained by us detecting the emotional resonation of someone with emotional patterns containing violent or aggressive sentiments.

Some people may simply be physiologically less able to detect others emotional field, at the extreme end of the range, to them others may not exist, they are the traditional definition of psychopaths, unable to empathise with others because they cannot feel that others exist emotionally. Others do not exist for them and they may simply treat others as utilitarian objects, we would not feel any particular empathy for a spade or screwdriver. Some people may be epigenetically primed to switch off this sensitivity, the predator cannot afford to feel pity for they prey or they cannot eat the prey. 


\subsection{Operation of Magnosensitivity in the Modern Environment}

Historically humans lived in hunter gatherer environments where we would know all the people we would meet on a regular basis, strangers were likely to be from opposing or competing groups and therefore dangerous. Our detection mechanisms have evolved to react in this way and while human plasticity has ensured we do not form a mob and attack every stranger we meet which would be rather inconvenient in urban environments. There are daily interactions that we take part in every day in rural but especially urban environments where we meet people we don't know, we still need to identify risk as much as in pre-industrial times. There would still be a biological reason for the physiology to have retained this sense.

It is not known whether or not and to what degree artificial radiation from electrical equipment may interfere or enhance interpersonal emotional data transfers.

\section{Future Questions}

\section{Examination of the Hypothesis by Scaling up}

While experimentally very challenging with current technology to prove, other circumstantial evidence can be considered; if we can see this happen between small groups of people in disorders, it may also occur on a larger collective scale, albeit with a proportionally slower cumulative action. Larger historically significant political movements appear to have some behavioural signs of this hypothesized effect. Pre-existing stress in the wider society may facilitate emotional contagion, the example of Germany in the 1930's can be used; Germany was a stressed nation suffering economic depression, internal strife, revolution and military defeat. It can be argued to have had a large number of distressed people running in an emotional state close to a "contagion" mode of phase transition since 1914. A combination of this and a leader with personality which had an unusually strong ability to project his own emotional patterns onto others was able to entrain others already experiencing prolonged elevated base levels of threat into catastrophic consequences. It is not known, but possible, that the fondness for large torchlight gatherings used by the Nazi party would be potential venues to expose large volumes of people to powerful emotion contagion fields to synchronise emotions. It is not known if frequency of participation in these large emotional assemblies makes subsequent synchronisations of emotions between participants easier.

It can be of interest to know whether the importance of the individual with unusual personality patterns can generate mass movements. Many other countries in the 1930's and 1940's also suffered intense stresses. This was expressed in different forms, a milder version of Fascism in Italy, warlords in China and Anarchism in preFranco Spain. Communism also produced mass psychoses or highly stochastic emotional contagions of a similar intensity capable of killing millions as in Germany under Hitler, and this may be linked to Stalin's ruthless personality. Russia had the traumatic civil war and famines following the collapse of the Russian Empire inducing possibly a similar level of collective trauma. A combination of strong personality projection by a leader with psychotic tendencies, widespread pre-existing social memes lacking empathy for parts of society who are labelled as "unacceptable", and ambient economic or inter-ethnic stress, may all be potential factors which can come together in a dangerous fashion.

While it has been hypothesised in this work is that emotional contagion may have a role in crowd formation, it is suspected but not known whether or not (if it can be validated) that it is significant in larger social movements, cultures and national behaviours. The mass emotional frenzy in Britain, Germany and France amongst the civilian population at the outset of the First World War does seem consistent with a larger emotional contagion phenomenon.

If this contagion hypothesis is demonstrable on a crowd scale, it raises further questions; when individuals become part of a crowd does the crowd now have a collective mind, and if so how much is retained in the subconscious when the crowd disperses? Does circulation of data in crowds only take place at crisis points such as crowds and disorders or does it also routinely transfer emotional data through lower activation levels of biomagnetic resonance and/or hypothetical quantum effects?

Other questions are: if longer term emotional data reservoirs can be demonstrated does emotional attachment to culture or religion imply an access link or key to a particular collective data storage mechanism or is there a larger data storage mechanism accessible to all groups; the universe is after all an open system. Research in future may clarify whether data circulates in a collective memory bank which survives the death of any one member of a group. 
As some multidimensional space time theory hypothesises 11 dimensions there could be potential for further research as to how dimensional structures and biophysics influences understanding channels of data transfers between individuals and groups.

\section{Summary}

Not always a negative phenomena? Large scale cognitive changes in groups have been historically observed in crowd situations of both violent groups as in riots and warfare and non-violent assemblies such as in sporting events or music concerts, it will be of interest to see if this hypothesis can clarify what a good "stage presence" or "leadership" is? This phenomena has been more perceptible when it operated with negative emotional content but it is proposed to be possibly a routine daily mechanism that we all experience at a lesser degree at lower energy levels while synchronising between people engaged in interpersonal interaction, group working, trading, co-operation and routine socialising.

There appears to be a sufficiently coherent interplay of biophysics, human structural features and cognitive functions to justify further research into a proposed meta cognitive phenomenon of an energy based channel of collective emotional transfer via the unconscious mind. This hypothesis, while unproved and posing substantial replication problems, gives a basis for further experimentation to explore this phenomenon through cross disciplinary inputs which may hopefully add extra insight for researchers into a historically frustrating collective phenomenon.

\section{References}

[1] Le Bon, G. (1897) The Crowd: A Study of the Popular Mind. Kessinger Publishing Co., Whitefish.

[2] Waddington, D.P., Jones, K. and Critcher, C. (1989) Flashpoints: Studies in Public Disorder. Routledge, London.

[3] Waddington, D. and King, M. (2005) The Disorderly Crowd: From Classical Psychological Reductionism to SocioContextual Theory-The Impact on Public Order Policing Strategies. The Howard Journal of Criminal Justice, 44, 490-503. http://dx.doi.org/10.1111/j.1468-2311.2005.00393.x

[4] Reicher, S. and Stott, C. (1998) Crowd Action as Intergroup Process: Introducing the Police Perspective. European Journal of Social Psychology, 28, 509-529. http://dx.doi.org/10.1002/(SICI)1099-0992(199807/08)28:4<509::AID-EJSP877>3.0.CO;2-C

[5] Reicher, S. (2001) The Psychology of Crowd Dynamics. In: Blackwell Handbook of Social Psychology: Group Processes, Blackwell Publishing, Malden, Massachusetts, 182-208.

[6] Reicher, S., Stott, C., Cronin, P. and Adang, O. (2004) An Integrated Approach to Crowd Psychology and Public Order Policing. Policing: An International Journal of Police Strategies \& Management, 27, 558-572. http://dx.doi.org/10.1108/13639510410566271

[7] Deco, G., Rolls, E., Romo, R., Chizmadzhev, Y.A., Indenbom, A.V. and Kuzmin, P.I. (2009) Stochastic Dynamics as a Principle of Brain Function. Progress in Neurobiology, 88, 1-16. http://dx.doi.org/10.1016/j.pneurobio.2009.01.006

[8] Patten, S. and Arboleda-Flórez, J. (2004) Epidemic Theory and Group Violence. Social Psychiatry and Psychiatric Epidemiology, 39, 853-856. http://dx.doi.org/10.1007/s00127-004-0867-9

[9] Smelser, N. (1962) Theory of Collective Behaviour. Routledge Publishing, London.

[10] Cannetti, E. (1984) Crowds and Power. Farrar Straus and Giroux, New York.

[11] Turner, J.C., Hogg, M.A., Oakes, P.J., Reicher, S.D. and Wetherell, M.S. (1987) Rediscovering the Social Group: A Self-Categorization Theory. Basil Blackwell, Oxford.

[12] Patten, S. (1999) Epidemics of Violence. Medical Hypotheses, 53, 217-220. http://dx.doi.org/10.1054/mehy.1998.0748

[13] Drury, J. and Reicher, S. (2000) Collective Action and Psychological Change: The Emergence of New Social Identities. British Journal of Social Psychology, 39, 579-604. http://dx.doi.org/10.1348/014466600164642

[14] Home Office (2011) An Overview of Recorded Crimes and Arrests Resulting from Disorder Events in August 2011. Home Office, London.

[15] Newton, J.W. and Mann, L. (1980) Crowd Size as a Factor in the Persuasion Process: A Study of Religious Crusade Meetings. Journal of Personality and Social Psychology, 39, 874-883. http://dx.doi.org/10.1037/0022-3514.39.5.874

[16] Amin, Y., Hamdi, E. and Eapen, V. (1997) Mass Hysteria in an Arab Culture. International Journal of Social Psychiatry, 43, 303-306.

[17] Bolton, K. (2011) http//hydrablog.csusm.edu/2011/08/after british riots conflictin.html 
[18] Mather, M. and Lighthall, N.R. (2012) Risk and Reward Are Processed Differently in Decisions Made Under Stress. Current Directions in Psychological Science, 21, 36-41. http://dx.doi.org/10.1177/0963721411429452

[19] Hill, P. (2008) Vibrational Communication in Animals. Harvard University Press, Cambridge, Massachusetts.

[20] Bargh, J.A., Chen, M. and Burrows, L. (1996) Automaticity of Social Behavior: Direct Effects of Trait Construct and Stereotype Activation on Action. Journal of Personality and Social Psychology, 71, 230-244. http://dx.doi.org/10.1037/0022-3514.71.2.230

[21] Dijksterhuis, A. (2004) Think Different: The Merits of Unconscious Thought in Preference Development and Decision Making. Journal of Personality and Social Psychology, 87, 586-598. http://dx.doi.org/10.1037/0022-3514.87.5.586

[22] Manly, T., Fish, J.E., Griffiths, S., Molenveld, M., Zhou, F.A. and Davis, G.J. (2014) Unconscious Priming of TaskSwitching Generalizes to an Untrained Task. PLoS ONE, 9, Article ID: e88416. http://dx.doi.org/10.1371/journal.pone.0088416

[23] Dimberg, U., Thunberg, M. and Elmehed, K. (2000) Unconscious Facial Reactions to Emotional Facial Expressions. Psychological Science, 11, 86-89. http://dx.doi.org/10.1111/1467-9280.00221

[24] Wang, S., Tsuchiya, N., New, J., Hurlemann, R. and Adolphs, R. (2014) Preferential Attention to Animals and People Is Independent of the Amygdala. Social Cognitive and Affective Neuroscience, Epub ahead of print. http://dx.doi.org/10.1093/scan/nsu065

[25] Hinzman, L. and Kelly, S.D. (2013) Effects of Emotional Body Language on Rapid Out-Group Judgments. Journal of Experimental Social Psychology, 49, 152-155. http://dx.doi.org/10.1016/j.jesp.2012.07.010

[26] Gawronski, B. and Bodenhausen, G.V. (2005) Accessibility Effects on Implicit Social Cognition: The Role of Knowledge Activation and Retrieval Experiences. Journal of Personality and Social Psychology, 89, 672-685. http://dx.doi.org/10.1037/0022-3514.89.5.672

[27] De Gelder, B., Snyder, J., Greve, D., Gerard, G. and Hadjikhani, N. (2004) Fear Fosters Flight: A Mechanism for Fear Contagion When Perceiving Emotion Expressed by a Whole Body. Proceedings of the National Academy of Sciences of the United States of America, 101, 16701-16706. http://dx.doi.org/10.1073/pnas.0407042101

[28] Carretié, L., Hinojosa, J.A., Mercado, F. and Tapia, M. (2005) Cortical Response to Subjectively Unconscious Danger. Neuroimage, 24, 615-623. http://dx.doi.org/10.1016/j.neuroimage.2004.09.009

[29] Haxby, J.V., Hoffman, E.A. and Gobbini, M.I. (2000) The Distributed Human Neural System for Face Perception. Trends in Cognitive Sciences, 4, 223-233. http://dx.doi.org/10.1016/S1364-6613(00)01482-0

[30] Tomasello, M., Carpenter, M., Call, J., Behne, T. and Moll, H. (2005) Understanding and Sharing Intentions: The Origins of Cultural Cognition. Behavioral and Brain Sciences, 28, 675-691. http://dx.doi.org/10.1017/S0140525X05000129

[31] Brosch, T., Pourtois, G., Sander, D. and Vuilleumier, P. (2011) Additive Effects of Emotional, Endogenous, and Exogenous Attention: Behavioral and Electrophysiological Evidence. Neuropsychologia, 49, 1779-1787. http://dx.doi.org/10.1016/j.neuropsychologia.2011.02.056

[32] Farroni, T., Csibra, G., Simion, F. and Johnson, M.H. (2002) Eye Contact Detection in Humans from Birth. Proceedings of the National Academy of Sciences of the United States of America, 99, 9602-9605. http://dx.doi.org/10.1073/pnas.152159999

[33] Ohman, A., Flykt, A. and Esteves, F. (2001) Emotion Drives Attention: Detecting the Snake in the Grass. Journal of Experimental Psychology: General, 130, 466-478. http://dx.doi.org/10.1037/0096-3445.130.3.466

[34] Totah, N.K., Jackson, M.E. and Moghaddam, B. (2013) Preparatory Attention Relies on Dynamic Interactions between Prelimbic Cortex and Anterior Cingulate Cortex. Cerebral Cortex, 23, 729-738. http://dx.doi.org/10.1093/cercor/bhs057

[35] Davila, A.F., Fleissner, G., Winklhofer, M. and Petersen, N. (2003) A New Model for a Magnetoreceptor in Homing Pigeons Based on Interacting Clusters of Superparamagnetic Magnetite. Physics and Chemistry of the Earth, Parts A/B/C, 28, 647-652. http://dx.doi.org/10.1016/S1474-7065(03)00118-9

[36] Presti, D. and Pettigrew, J.D. (1980) Ferromagnetic Coupling to Muscle Receptors as a Basis for Geomagnetic Field Sensitivity in Animals. Nature, 285, 99-101. http://dx.doi.org/10.1038/285099a0

[37] Jacob, H., Brück, C., Domin, M., Lotze, M. and Wildgruber, D. (2014) I Can’t Keep Your Face and Voice out of My Head: Neural Correlates of an Attentional Bias toward Nonverbal Emotional Cues. Cerebral Cortex, 24, 1460-1473. http://dx.doi.org/10.1093/cercor/bhs417

[38] Rautkylä, E., Puolakka, M. and Halonen, L. (2012) Alerting Effects of Daytime Light Exposure-A Proposed Link between Light Exposure and Brain Mechanisms. Lighting Research and Technology, 44, 238-252. http://dx.doi.org/10.1177/1477153511409294

[39] Vandewalle, G., Schwartz, S., Grandjean, D., Wuillaume, C., Balteau, E., Degueldre, C., Schabus, M., Phillips, C., 
Luxen, A., Dijk, D.J. and Maquet, P. (2010) Spectral Quality of Light Modulates Emotional Brain Responses in Humans. Proceedings of the National Academy of Sciences of the United States of America, 107, 19549-19554. http://dx.doi.org/10.1073/pnas.1010180107

[40] Conrad, C.D. and Stumpf, W.E. (1975) Direct Visual Input to the Limbic System: Crossed Retinal Projections to the Nucleus Anterodorsalis Thalami in the Tree Shrew. Experimental Brain Research, 23, 141-149. http://dx.doi.org/10.1007/BF00235456

[41] Rautkyä, E., Puolakka, M. and Halonen, L. (2011) Alerting Effects of Daytime Light Exposure-A Proposed Link between Light Exposure and Brain Mechanisms. Lighting Research and Technology.

[42] Aspect, A., Grangier, P. and Roger, G. (1982) Experimental Realization of Einstein-Podolsky-Rosen-Bohm Gedankenexperiment: A New Violation of Bell's Inequalities. Physical Review Letters, 49, 91-94. http://dx.doi.org/10.1103/PhysRevLett.49.91

[43] George, M.S., Wassermann, E.M., Williams, W.A., Steppel, J., Pascual-Leone, A., Basser, P., Hallet, M. and Post, R.M. (1996) Changes in Mood and Hormone Levels after Rapid-Rate Transcranial Magnetic Stimulation (rTMS) of the Prefrontal Cortex. The Journal of Neuropsychiatry and Clinical Sciences, 8, 172-180.

[44] Lopez-Ibor, J.J., López-Ibor, M.I. and Pastrana, J.I. (2008) Transcranial Magnetic Stimulation. Current Opinion in Psychiatry, 21, 640-644. http://dx.doi.org/10.1097/YCO.0b013e3283136a0c

[45] Nummenmaa, L., Glerean, E., Hari, R. and Hietanen, J.K. (2014) Bodily Maps of Emotions. Proceedings of the National Academy of Sciences of the United States of America, 111, 646-651. http://dx.doi.org/10.1073/pnas.1321664111

[46] Otsuka, K., Oinuma, S., Cornélissen, G., Weydahl, A., Ichimaru, Y., Kobayashi, M., Yano, S., Holmeslet, B., Hansen, T.L., Mitsutake, G., Engebretson, M.J., Schwartzkopff, O. and Halberg, F. (2001) Alternating Light-Darkness-Influenced Human Electrocardiographic Magnetoreception in Association with Geomagnetic Pulsations. Biomedicine \& Pharmacotherapy, 55, 63s-75s. http://dx.doi.org/10.1016/S0753-3322(01)90007-1

[47] Watanabe, Y., Cornélissen, G., Halberg, F., Otsuka, K. and Ohkawa, S.I. (2000) Associations by Signatures and Coherences between the Human Circulation and Helio- and Geomagnetic Activity. Biomedicine \& Pharmacotherapy, 55, s76-s83. http://dx.doi.org/10.1016/S0753-3322(01)90008-3

[48] Nishimura, T., Tada, H., Nakatani, E., Matsuda, K., Teramukai, S. and Fukushima, M. (2014) Stronger Geomagnetic Fields May Be a Risk Factor of Male Suicides. Psychiatry and Clinical Neurosciences, 68, 404-409. http://dx.doi.org/10.1111/pcn.12149

[49] Glover, P.M. and Bowtell, R. (2008) Measurement of Electric Fields Induced in a Human Subject Due to Natural Movements in Static Magnetic Fields or Exposure to Alternating Magnetic Field Gradients. Physics in Medicine and Biology, 53, 361. http://dx.doi.org/10.1088/0031-9155/53/2/005

[50] Rainville, P., Bechara, A., Naqvi, N. and Damasio, A. (2006) Basic Emotions Are Associated with Distinct Patterns of Cardiorespiratory Activity. International Journal of Psychophysiology, 61, 5-18.

[51] Schmidt, R.C. and Richardson, M.J. (2008) Dynamics of Interpersonal Coordination. In: Coordination: Neural, Behavioral and Social Dynamics, Springer, Berlin Heidelberg, 281-308.

[52] Shea, N., Boldt, A., Bang, D., Yeung, N., Heyes, C. and Frith, C.D. (2014) Supra-Personal Cognitive Control and Metacognition. Trends in Cognitive Sciences, 18, 186-193. http://dx.doi.org/10.1016/j.tics.2014.01.006

[53] Pecenka, N. and Keller, P.E. (2011) The Role of Temporal Prediction Abilities in Interpersonal Sensorimotor Synchronization. Experimental Brain Research, 211, 505-515. http://dx.doi.org/10.1007/s00221-011-2616-0

[54] Bargh, J.A., Schwader, K.L., Hailey, S.E., Dyer, R.L. and Boothby, E.J. (2012) Automaticity in Social-Cognitive Processes. Trends in Cognitive Sciences, 16, 593-605. http://dx.doi.org/10.1016/j.tics.2012.10.002

[55] Close, J. (2012) Are Stress Responses to Geomagnetic Storms Mediated by the Cryptochrome Compass System? Proceedings of the Royal Society B: Biological Sciences, 279, 2081-2090. http://dx.doi.org/10.1098/rspb.2012.0324

[56] Rusov, V., Lukin, K.A., Zelentsova, T.N., Linnik, E.P., Beglaryan, M.E., Smolyar, V.P., Filippov, M. and Vachev, B. (2012) Can Resonant Oscillations of the Earth Ionosphere Influence the Human Brain Biorhythm? arXiv preprint arXiv:1208.4970.

[57] Freake, M.J., Muheim, R. and Phillips, J.B. (2006) Magnetic Maps in Animals: A Theory Comes of Age? The Quarterly Review of Biology, 81, 327-347. http://dx.doi.org/10.1086/511528

[58] Azcáratea, T., Sánchez de la Peñac, B. and Martíneza, J. (2012) Temporal Variation of the Arterial Pressure in Healthy Young People and Its Relation to Geomagnetic Activity in Mexico. Advances in Space Research, 50, 1310-1315. http://dx.doi.org/10.1016/j.asr.2012.06.015

[59] Radin, D.I. (1992) Evidence for Relationship between Geomagnetic Field Fluctuations and Skilled Physical Performance. Artigo Apresentado na 11a Reunião Anual da Sociedade de Explorações Científicas, Princeton, Nova Jersey.

[60] Volpe, P. (2003) Interactions of Zero-Frequency and Oscillating Magnetic Fields with Biostructures and Biosystems. 
Photochemical \& Photobiological Sciences, 2, 637-648. http://dx.doi.org/10.1039/b212636b

[61] Berk, M., Dodd, S. and Henry, M. (2005) Do Ambient Electromagnetic Fields Affect Behaviour? A Demonstration of the Relationship between Geomagnetic Storm Activity and Suicide. Bioelectromagnetics, 27, 151-155. http://dx.doi.org/10.1002/bem.20190

[62] Liboff, A.R. (2013). Why Are Living Things Sensitive to Weak Magnetic Fields? Electromagnetic Biology and Medicine, 1-5.

[63] Oxley, D., Smith, K., Alford, J., Hibbing, M., Miller, J., Scalora, M., Hatemi, P. and Hibbing, J. (2008) Political Attitudes Vary with Physiological Traits. Science, 321, 1667-1670. http://dx.doi.org/10.1126/science.1157627

[64] Abraham, R. (2000) Vibrational Resonance and Cognitive Internalization. For: Proceedings of Einstein Days in Visva Bharati University, Santiniketan, West Bengal, International Seminar on Cognitive Processes of Internalization in Humanities and Sciences, 15-18 March 2000.

[65] Norina, S., Rastopov, S. and Popp, F. (2000) Coherent Vibrations of Cells under Magnetic Influences. Proc. SPIE 3915, Coherence Domain Optical Methods in Biomedical Science and Clinical Applications IV, 214, 28 April 2000.

[66] Cifra, M., Vani, J., Kucera, O., Hasek, J., Frydlova, A., Jelnek, F., Saroch, J. and Pokorny, J. (2007) Biophotonics: Optical Science and Engineering for the 21st Century. Progress in Electromagnetics Research Symposium 2007, Prague, 27-30 August 2007

[67] Cikara, M., Jenkins, A.C., Dufour, A. and Saxe, R. (2014) Reduced Self-Referential Neural Response during Intergroup Competition Predicts Competitor Harm. NeuroImage, 96, 36-43. http://dx.doi.org/10.1016/j.neuroimage.2014.03.080

[68] Sullins, E.S. (1991) Emotional Contagion Revisited: Effects of Social Comparison and Expressive Style on Mood Convergence. Personality and Social Psychology Bulletin, 17, 166-174. http://dx.doi.org/10.1177/014616729101700208

[69] Hagan, C.C., Woods, W., Johnson, S., Calder, A.J., Green, G.G. and Young, A.W. (2009) MEG Demonstrates a Supra-Additive Response to Facial and Vocal Emotion in the Right Superior Temporal Sulcus. Proceedings of the National Academy of Sciences of the United States of America, 106, 20010-20015. http://dx.doi.org/10.1073/pnas.0905792106

[70] Grossman, E.D. and Blake, R. (2001) Brain Activity Evoked by Inverted and Imagined Biological Motion. Vision Research, 41, 1475-1482. http://dx.doi.org/10.1016/S0042-6989(00)00317-5

[71] Ainsworth, C. (2007) Cilia: Tails of the Unexpected. Nature, 448, 638-641. http://dx.doi.org/10.1038/448638a

[72] Bargmann, C.I. (2006) Comparative Chemosensation from Receptors to Ecology. Nature, 444, $295-301$. http://dx.doi.org/10.1038/nature05402

[73] McPhail, C. and Wohlstein, R.T. (1983) Individual and Collective Behaviors within Gatherings, Demonstrations, and Riots. Annual Review of Sociology, 9, 579-600. http://dx.doi.org/10.1146/annurev.so.09.080183.003051

[74] McPhail, C. (1991) The Myth of the Madding Crowd. Transaction Publishers, Piscataway.

[75] Costantini, D., Monaghan, P. and Metcalfe, N.B. (2012) Early Life Experience Primes Resistance to Oxidative Stress. Journal of Experimental Biology, 215, 2820-2826. http://dx.doi.org/10.1242/jeb.072231

[76] McGowan, P., Sasaki, A., D’Alessio, A., Dymov, S., Labonté, B., Szyf, M., Turecki, G. and Meaney, M. (2009) Epigenetic Regulation of the Glucocorticoid Receptor in Human Brain Associates with Childhood Abuse. Nature Neuroscience, 12, 342-348. http://dx.doi.org/10.1038/nn.2270

[77] Kleim, J.A., Chan, S., Pringle, E., Schallert, K., Procaccio, V., Jimenez, R. and Cramer, S.C. (2006) BDNF val66met Polymorphism Is Associated with Modified Experience-Dependent Plasticity in Human Motor Cortex. Nature Neuroscience, 9, 735-737. http://dx.doi.org/10.1038/nn1699

[78] Ame, J., Halloy, J., Rivault, C., Detrain, C. and Deneubourg, J. (2006) Collegial Decision Making Based on Social Amplification Leads to Optimal Group Formation. Proceedings of the National Academy of Sciences of the United States of America, 103, 5835-5840. http://dx.doi.org/10.1073/pnas.0507877103

[79] Brewer, M.B. (1999) The Psychology of Prejudice: Ingroup Love and Outgroup Hate? Journal of Social Issues, 55, 429-444. http://dx.doi.org/10.1111/0022-4537.00126

[80] Dumas, G., Chavez, M., Nadel, J. and Martinerie, J. (2012) Anatomical Connectivity Influences both Intra- and InterBrain Synchronizations. PLoS ONE, 7, Article ID: e36414. http://dx.doi.org/10.1371/journal.pone.0036414

[81] Hexmoor, H. (2011) Crowds and Spontaneous Collaboration. Proceedings of IC-AI, Las Vegas, NV, 18-21 July 2011, Las Vegas, Nevada.

[82] White, R. (2006) Swarming and the Social Dynamics of Group Violence. Trends and Issues in Criminal Justice, No. 326. 
[83] Aunger, R. (2000) Darwinizing Culture the Status of Memetics as a Science. Oxford University Press, Oxford.

[84] Tek, C. and Ulug, B. (2001) Religiosity and Religious Obsessions in Obsessive-Compulsive Disorder. Psychiatry Research, 104, 99-108. http://dx.doi.org/10.1016/S0165-1781(01)00310-9

[85] Previc, F.H. (2006) The Role of the Extrapersonal Brain Systems in Religious Activity. Consciousness and Cognition, 15, 500-539. http://dx.doi.org/10.1016/j.concog.2005.09.009

[86] Williams, L.E. and Bargh, J.A. (2008) Experiencing Physical Warmth Promotes Interpersonal Warmth. Science, 322, 606-607. http://dx.doi.org/10.1126/science.1162548

[87] Lacks, R.D., Gordon, J.A. and Mccue, C.M. (2005) Who, What, and When: A Descriptive Examination of Crowd Formation, Crowd Behavior, and Participation with Law Enforcement at Homicide Scenes in One City. American Journal of Criminal Justice, 30, 1-20. http://dx.doi.org/10.1007/BF02885878

[88] Zanello, S.B., Jackson, D.M. and Holick, M.F. (2000) Expression of the Circadian Clock Genes Clock and Period 1 in Human Skin. The Journal of Investigative Dermatology, 115, 757-760. http://dx.doi.org/10.1046/j.1523-1747.2000.00121.x

[89] Li, J., Gao, Q., Zhou, J., Li, X., Zhang, M. and Shen, M. (2014) Bias or Equality? Unconscious Thought Equally Integrates Temporally Scattered Information. Consciousness and Cognition, 25, 77-87. http://dx.doi.org/10.1016/j.concog.2014.01.012

[90] Butler, E., Egloff, B., Wilhelm, F., Smith, N., Erickson, E. and Gross, J. (2003) The Social Consequences of Expressive Suppression. Emotion, 3, 48-67. http://dx.doi.org/10.1037/1528-3542.3.1.48

[91] MacArthur, R. and Pianka, E. (1966) On Optimal Use of a Patchy Environment. American Naturalist, 100, $603-609$. http://dx.doi.org/10.1086/282454

[92] Brown, J.H., Gillooly, J.F., Allen, A.P., Savage, V.M. and West, G.B. (2004) Toward a Metabolic Theory of Ecology. Ecology, 85, 1771-1789. http://dx.doi.org/10.1890/03-9000

[93] Donaldson, Z. and Young, L. (2008) Oxytocin, Vasopressin, and the Neurogenetics of Sociality. Science, 322, $900-904$. http://dx.doi.org/10.1126/science.1158668

[94] Rosenblum, M. and Pikovsky, A. (2003) Synchronization: From Pendulum Clocks to Chaotic Lasers and Chemical Oscillators. Contemporary Physics, 44, 401-416. http://dx.doi.org/10.1080/00107510310001603129

[95] Buzsaki, G. (2006) Rhythms of the Brain. Oxford University Press, Oxford. http://dx.doi.org/10.1093/acprof:oso/9780195301069.001.0001

[96] Maeda, K., Henbest, K.B., Cintolesi, F., Kuprov, I., Rodgers, C.T., Liddell, P.A., Gust, D., Timmel, C.R. and Hore, P.J. (2008) Chemical Compass Model of Avian Magnetoreception. Nature, 453, 387-390. http://dx.doi.org/10.1038/nature06834

[97] Heyers, D., Luksch, H., Güntürkün, O. and Mouritsen, H. (2007) A Visual Pathway Links Brain Structures Active during Magnetic Compass Orientation in Migratory Birds. PLoS ONE, 2, Article ID: e937. http://dx.doi.org/10.1371/journal.pone.0000937

[98] Partonen, T. (2012) Hypothesis: Cryptochromes and Brown Fat Are Essential for Adaptation and Affect Mood and Mood-Related Behaviors. Frontiers in Neurology, 3, 157.

[99] Weaver, J., Vaughan, T. and Astumian, R. (2000) Biological Sensing of Small Field Differences by Magnetically Sensitive Chemical Reactions. Nature, 405, 707-709. http://dx.doi.org/10.1038/35015128

[100] Vaughan, T. and Weaver, J.C. (2005) Molecular Change Signal-to-Noise Criteria for Interpreting Experiments Involving Exposure of Biological Systems to Weakly Interacting Electromagnetic Fields. Bioelectromagnetics, 26, 305-322. http://dx.doi.org/10.1002/bem.20094

[101] Pitcher, T., Partridge, B. and Wardle, C. (1976) A Blind Fish Can School. Science, 194, 963-965. http://dx.doi.org/10.1126/science.982056.

[102] Camazine, S., Deneubourg, J., Franks, N., Sneyd, J., Theraulaz, G. and Bonabeau, E. (2001) Self-Organization in Biological Systems. Princeton University Press, Princeton.

[103] Johnsen, S. and Lohmann, K.J. (2005) The Physics and Neurobiology of Magnetoreception. Nature Reviews Neuroscience, 6, 703-712. http://dx.doi.org/10.1038/nrn1745

[104] Norina, S.B., Rastopov, S.F. and Popp, F.A. (2000) Coherent Vibrations of Cells under Magnetic Influences. Proceedings SPIE, 3915, 214-221. http://dx.doi.org/10.1117/12.384158

[105] Moore, C.I. and Cao, R. (2008) The Hemo-Neural Hypothesis: On the Role of Blood Flow in Information Processing. Journal of Neurophysiology, 99, 2035-2047. http://dx.doi.org/10.1152/jn.01366.2006

[106] Kirschvink, J.L, Walker, M.M. and Diebel, C.E. (2001) Magnetite-Based Magnetoreception. Current Opinion in Neurobiology, 11, 462-467. http://dx.doi.org/10.1016/S0959-4388(00)00235-X 
[107] Kirschvink, J.L., Kobayashi-Kirschvink, A. and Woodford, B.J. (1992) Magnetite Biomineralization in the Human Brain. Proceedings of the National Academy of Sciences of the United States of America, 89, 7683-7687. http://dx.doi.org/10.1073/pnas.89.16.7683

[108] Carrubba, S., Frilot II, C., Chesson Jr., A.L. and Marino, A.A. (2007) Evidence of a Nonlinear Human Magnetic Sense. Neuroscience, 144, 356-367. http://dx.doi.org/10.1016/j.neuroscience.2006.08.068

[109] Frilot II, C., Carrubba, S. and Marino, A.A. (2014) Sensory Transduction of Weak Electromagnetic Fields: Role of Glutamate Neurotransmission Mediated by NMDA Receptors. Neuroscience, 258, 184-191. http://dx.doi.org/10.1016/j.neuroscience.2013.11.009

[110] Wiltschko, R. and Wiltschko, W. (2006) Magnetoreception. BioEssays, 28, 157-168. http://dx.doi.org/10.1002/bies.20363

[111] Baker, R.R., Mather, J.G. and Kennaugh, J.H. (1983) Magnetic Bones in Human Sinuses. Nature, 301, 79-80.

[112] Wiesenfeld, K. and Moss, F. (1995) Stochastic Resonance and the Benefits of Noise: From Ice Ages to Crayfish and SQUIDs. Nature, 373, 33-36.

[113] Foley, L.E., Gegear, R.J. and Reppert, S.M. (2011) Human Cryptochrome Exhibits Light-Dependent Magnetosensitivity. Nature Communications, 2, 356. http://dx.doi.org/10.1038/ncomms1364

[114] Otsuka, K., Yamanaka, T., Cornélissen, G., Breus, T., Chibisov, S.M., Baevsky, R., Siegelová, J., Fiser, B. and Halberg, F. (2000) Altered Chronome of Heart Rate Variability during Span of High Magnetic Activity. Scripta Medica (Brno), 73, 111-116.

[115] Castaneda, J. and Segerstrom, S. (2004) Effect of Stimulus Type and Worry on Physiological Response to Fear. Journal of Anxiety Disorders, 18, 809-823. http://dx.doi.org/10.1016/j.janxdis.2003.10.003

[116] Hayut, I., Puzenko, A., Ben Ishai, P., Polsman, A., Agranat, A.J. and Feldman, Y. (2013) The Helical Structure of Sweat Ducts: Their Influence on the Electromagnetic Reflection Spectrum of the Skin. IEEE Transactions on Terahertz Science and Technology, 3, 207-215. http://dx.doi.org/10.1109/TTHZ.2012.2227476

[117] Chizmadzhev, Y., Indenbom, A., Kuzmin, P., Galichenko, S., Weaver, J. and Potts, R. (1998) Electrical Properties of Skin at Moderate Voltages. Biophysical Journal, 74, 843-856. http://dx.doi.org/10.1016/S0006-3495(98)74008-1

[118] Ney, M. and Abdulhalim, I. (2011) Modeling of Reflectometric and Ellipsometric Spectra from the Skin in the Terahertz and Submillimeter Waves Region. Journal of Biomedical Optics, 16, Article ID: 067006. http://dx.doi.org/10.1117/1.3592779

[119] Hayut, I., Ishai, P.B., Agranat, A.J. and Feldman, Y. (2014) Circular Polarization Induced by the Three-Dimensional Chiral Structure of Human Sweat Ducts. Physical Review E, 89, Article ID: 042715. http://dx.doi.org/10.1103/PhysRevE.89.042715

[120] Maeda, K., Robinson, A.J., Henbest, K.B., Hogben, H.J., Biskup, T., Ahmad, M., Schleicher, E., Weber, S., Timmel, C.R. and Hore, P.J. (2012) Magnetically Sensitive Light-Induced Reactions in Cryptochrome Are Consistent with Its Proposed Role as a Magnetoreceptor. Proceedings of the National Academy of Sciences of the United States of America, 109, 4774-4779.

[121] Miller, I. and Lonetree, B. (2013) The Sedona Effect: Correlations between Geomagnetic Anomalies, EEG Brainwaves \& Schumann Resonance. Journal of Consciousness Exploration \& Research, 4.

[122] Irmak, M. (2010) Multifunctional Merkel Cells Their Roles in Electromagnetic Reception, Finger-Print Formation, Reiki, Epigenetic Inheritance and Hair Form. Medical Hypotheses, 75, 162-168. http://dx.doi.org/10.1016/j.mehy.2010.02.011

[123] Soh, K. (2004) Bonghan Duct and Acupuncture Meridian as Optical Channel of Biophoton. Journal of the Korean Physical Society, 45, 1196-1198.

[124] Soh, K. (2009) Bonghan Circulatory System as an Extension of Acupuncture Meridians. Journal of Acupuncture and Meridian Studies, 2, 93-106. http://dx.doi.org/10.1016/S2005-2901(09)60041-8

[125] Byung-Cheon Lee, K.W.K., Kwang-Sup Soh (2009) Visualizing the Network of Bonghan Ducts in the Omentum and Peritoneum by Using Trypan Blue. Journal of Acupuncture and Meridian Studies, 2, 66-70. http://dx.doi.org/10.1016/S2005-2901(09)60017-0

[126] Kwon, Y.W., Lee, C.H., Choi, D.H. and Jin, J.I. (2009) Materials Science of DNA. Journal of Materials Chemistry, 19, 1353-1380. http://dx.doi.org/10.1039/b808030e

[127] Ng, B.S.W., Schroeder, T. and Kayser, C. (2012) A Precluding But Not Ensuring Role of Entrained Low-Frequency Oscillations for Auditory Perception. The Journal of Neuroscience, 32, 12268-12276. http://dx.doi.org/10.1523/JNEUROSCI.1877-12.2012

[128] Achimescu, S. and Lipan, O. (2006) Signal Propagation in Nonlinear Stochastic Gene Regulatory Networks. IEE Proceedings of Systems Biology, 153, 120-134. http://dx.doi.org/10.1049/ip-syb:20050027 
[129] Oschmann, J. (2002) Clinical Aspects of Biological Fields: An Introduction for Health Care Professionals. Journal of Bodywork and Movement Therapies, 6, 117-125. http://dx.doi.org/10.1054/jbmt.2001.0259

[130] Feldman, Y., Puzenko, A., Ishai, P.B., Caduff, A. and Agranat, A.J. (2008) Human Skin as Arrays of Helical Antennas in the Millimeter and Submillimeter Wave Range. Physical Review Letters, 100, Article ID: 128102. http://dx.doi.org/10.1103/PhysRevLett.100.128102

[131] Abdulhalim, I. and Ney, M. (2010) Modeling of Reflectometric and Ellipsometric Spectra from the Skin in the Terahertz and Submillimeter Waves Region. Journal of Biomedical Optics, 16, Article ID: 067006.

[132] Seto, A., Kusaka, C., Nakazato, S., Huang, W.R., Sato, T., Hisamitsu, T. and Takeshige, C. (1992) Detection of Extraordinary Large Bio-Magnetic Field Strength from Human Hand during External Qi Emission. Acupuncture and Electro-Therapeutics Research International Journal, 17, 75-94.

[133] Kokubo, H., Yamamoto, M., Hirasawa, M., Kawano, K., Furukawa, M. and Sakaida, H. (1999) Review on Recent Measurements of Anomalous Bio-Magnetic Fields. Journal of International, Society of Life Information Science, 17, 20-25.

[134] Risch, N., Burchard, E., Ziv, E. and Tang, H. (2002) Categorization of Humans in Biomedical Research: Genes, Race and Disease. Genome Biology, 3, 1-12. http://dx.doi.org/10.1186/gb-2002-3-7-comment2007

[135] Dimitrova, S. (2006) Relationship between Human Physiological Parameters and Geomagnetic Variations of Solar Origin. Advances in Space Research, 37, 1251-1257.

[136] Brown, G.R., Dickins, T.E., Sear, R. and Laland, K.N. (2011) Evolutionary Accounts of Human Behavioural Diversity. Philosophical Transactions of the Royal Society B: Biological Sciences, 366, 313-324. http://dx.doi.org/10.1098/rstb.2010.0267

[137] Bohacek, J., Gapp, K., Saab, B.J. and Mansuy, I.M. (2013) Transgenerational Epigenetic Effects on Brain Functions. Biological Psychiatry, 73, 313-320. http://dx.doi.org/10.1016/j.biopsych.2012.08.019

[138] Jammes, H., Junien, C. and Chavatte-Palmer, P. (2010) Epigenetic Control of Development and Expression of Quantitative Traits. Reproduction, Fertility and Development, 23, 64-74. http://dx.doi.org/10.1071/RD10259

[139] Storz, J., Scott, G. and Cheviron, Z. (2010) Phenotypic Plasticity and Genetic Adaptation to High-Altitude Hypoxia in Vertebrates. Journal of Experimental Biology, 213, 4125-4136. http://dx.doi.org/10.1242/jeb.048181

[140] Labie, D. and Elion, J. (2012) Genetics of Adaptation to High Altitude. Wiley Online Library, ELS. file:///C:/Users/Owner/Downloads/Labie\%20Elion\%20eLS\%20Altitude\%202012.pdf

[141] Meyer-Lindenberg, A., Ziemann, U., Hajak, G., Cohen, L. and Berman, K.F. (2002) Transitions between Dynamical States of Differing Stability in the Human Brain. Proceedings of the National Academy of Sciences of the United States of America, 99, 10948-10953. http://dx.doi.org/10.1073/pnas.162114799

[142] McDermott, R., Fowler, J.H. and Smirnov, O. (2008) On the Evolutionary Origin of Prospect Theory Preferences. Journal of Politics, 70, 335-350. http://dx.doi.org/10.1017/S0022381608080341

[143] Buka, S.L., Stichick, T.L., Birdthistle, I. and Earls, F.J. (2001) Youth Exposure to Violence Prevalence, Risks, and Consequences. American Journal of Orthopsychiatry, 71, 298-310. http://dx.doi.org/10.1037/0002-9432.71.3.298

[144] Hoek, H.W., Brown, A.S. and Susser, E. (1998) The Dutch Famine and Schizophrenia Spectrum Disorders. Social Psychiatry and Psychiatric Epidemiology, 33, 373-379. http://dx.doi.org/10.1007/s001270050068

[145] Shorter, J. and Lindquist, S. (2005) Prions as Adaptive Conduits of Memory and Inheritance. Nature Reviews Genetics, 6, 435-450. http://dx.doi.org/10.1038/nrg1616

[146] Ayton, S., Lei, P., Adlard, P.A., Volitakis, I., Cherny, R.A., Bush, A.I. and Finkelstein, D.I. (2014) Iron Accumulation Confers Neurotoxicity to a Vulnerable Population of Nigral Neurons: Implications for Parkinson's Disease. Molecular Neurodegeneration, 9, 27. http://dx.doi.org/10.1186/1750-1326-9-27

[147] Berg, D., Gerlach, M., Youdim, M.B.H., Double, K.L., Zecca, L., Riederer, P. and Becker, G. (2002) Brain Iron Pathways and Their Relevance to Parkinson's Disease. Journal of Neurochemistry, 80, 719. http://dx.doi.org/10.1046/j.0022-3042.2001.00742.x

[148] Zheng, H.W., Wang, R.B., Qiao, L.K. and Du, Y. (2014) The Molecular Dynamics of Neural Metabolism during the Action Potential. Science China Technological Sciences, 57, 857-863. http://dx.doi.org/10.1007/s11431-014-5530-4

[149] Achterhold, K. and Parak, F. (2003) Protein Dynamics: Determination of Anisotropic Vibrations at the Haem Iron of Myoglobin. Journal of Physics: Condensed Matter, 15, S1683. http://dx.doi.org/10.1088/0953-8984/15/18/302

[150] Beldade, P., Mateus, A. and Keller, R. (2011) Evolution and Molecular Mechanisms of Adaptive Developmental Plasticity. Molecular Ecology, 20, 1347-1363. http://dx.doi.org/10.1111/j.1365-294X.2011.05016.X

[151] Duncan, E.J., Gluckman, P.D. and Dearden, P.K. (2014) Epigenetics, Plasticity, and Evolution: How Do We Link Epigenetic Change to Phenotype? Journal of Experimental Zoology Part B: Molecular and Developmental Evolution, 322, 208-220. http://dx.doi.org/10.1002/jez.b.22571 
[152] Misra, J., Sinha, A. and Shit, G. (2011) Mathematical Modeling of Blood Flow in a Porous Vessel Having Double Stenoses in the Presence of an External Magnetic Field. International Journal of Biomathematics, 4, 207. http://dx.doi.org/10.1142/S1793524511001428

[153] Zecca, L., Shima, T., Stroppolo, A., Goj, C., Battiston, G., Gerbasi, R., Sama, T. and Swartz, H. (1996) Interaction of Neuromelanin and Iron in Substantia Nigra and Other Areas of Human Brain. Neuroscience, 73, 407-415. http://dx.doi.org/10.1016/0306-4522(96)00047-4

[154] Achterhold, K., Keppler, C., Ostermann, A., van Bürck, U., Sturhahn, W., Alp, E.E. and Parak, F.G. (2002) Vibrational Dynamics of Myoglobin Determined by the Phonon-Assisted Mössbauer Effect. Physical Review E, 65, Article ID: 051916. http://dx.doi.org/10.1103/PhysRevE.65.051916

[155] Tong, Y.J., Hocke, L.M., Licata, S.C. and de B. Frederick, B. (2012) Low-Frequency Oscillations Measured in the Periphery with Near-Infrared Spectroscopy Are Strongly Correlated with Blood Oxygen Level-Dependent Functional Magnetic Resonance Imaging Signals. Journal of Biomedical Optics, 17, Article ID: 106004. http://dx.doi.org/10.1117/1.JBO.17.10.106004

[156] Bison, G., Wynands, R. and Weis, A. (2003) A Laser-Pumped Magnetometer for the Mapping of Human Cardiomagnetic Fields. Applied Physics B, 76, 325-328. http://dx.doi.org/10.1007/s00340-003-1120-z

[157] Burleson, K. and Schwartz, G. (2005) Cardiac Torsion and Electromagnetic Fields: The Cardiac Bioinformation Hypothesis. Medical Hypotheses, 64, 1109-1116. http://dx.doi.org/10.1016/j.mehy.2004.12.023

[158] Bortkiewicz, A., Gadzicka, E. and Zmyslony, M. (1996) Heart Rate Variability in Workers Exposed to Medium-Frequency Electromagnetic Fields. Journal of the Autonomic Nervous System, 59, 91-97. http://dx.doi.org/10.1016/0165-1838(96)00009-4

[159] Salmi, J., et al. (2013) The Brains of High Functioning Autistic Individuals Do Not Synchronize with Those of Others. NeuroImage, Clinical, 3, 489-497.

[160] Kostyuk, N., et al. (2011). Gas Discharge Visualization: An Imaging and Modeling Tool for Medical Biometrics. Journal of Biomedical Imaging, 2011, 3.1-7.

[161] McCraty, R., Atkinson, M., Tomasino, D. and Tiller, W.A. (1998) The Electricity of Touch: Detection and Measurement of Cardiac Energy Exchange between People. In: Brain and Values: Is a Biological Science of Values Possible, Lawrence Erlbaum Associates Publishers, Mahwah, NJ, 359-379.

[162] Feigin, V.L., Parmar, P.G., Barker-Collo, S., Bennett, D.A., Anderson, C.S., Thrift, A.G., et al. (2014) Geomagnetic Storms Can Trigger Stroke: Evidence from 6 Large Population-Based Studies in Europe and Australasia. Stroke, 45, 1639-1645. http://dx.doi.org/10.1161/STROKEAHA.113.004577

[163] Jozsa, R., Halberg, F., Cornélissen, G., Zeman, M., Kazsaki, J., Csernus, V., Amory-Mazaudin, C., et al. (2005) Chronomics, Neuroendocrine Feedsidewards and the Recording and Consulting of Nowcasts-Forecasts of Geomagnetics. Biomedicine \& Pharmacotherapy, 59, S24-S30. http://dx.doi.org/10.1016/S0753-3322(05)80006-X

[164] Pearsall, P., Schwartz, G.E. and Russek, L.G. (2000) Changes in Heart Transplant Recipients that Parallel the Personalities of Their Donors. Integrative Medicine, 2, 65-72. http://dx.doi.org/10.1016/S1096-2190(00)00013-5

[165] Grassi-Schultheiss, P.P., Heller, F. and Dobson, J. (1997) Analysis of Magnetic Material in the Human Heart, Spleen and Liver. Biometals, 10, 351-355. http://dx.doi.org/10.1023/A:1018340920329

[166] Winklhofer, M. (2005) Biogenic Magnetite and Magnetic Sensitivity in Organisms-From Magnetic Bacteria to Homing Pigeons. Magnetohydrodynamics, 41, 295-304.

[167] Winklhofer, M. (2007) Magnetite-Based Magnetoreception in Higher Organisms. In: Magnetoreception and Magnetosomes in Bacteria, Springer, Berlin, 301-314. http://dx.doi.org/10.1007/7171_048

[168] Critchley, H.D. (2005) Neural Mechanisms of Autonomic, Affective, and Cognitive Integration. Journal of Comparative Neurology, 493, 154-166. http://dx.doi.org/10.1002/cne.20749

[169] Spapé, M.M., Kivikangas, J.M., Järvelä, S., Kosunen, I., Jacucci, G. and Ravaja, N. (2013) Keep Your Opponents Close: Social Context Affects EEG and fEMG Linkage in a Turn-Based Computer Game. PLoS ONE, 8, Article ID: e78795. http://dx.doi.org/10.1371/journal.pone.0078795

[170] Hatfield, E., Carpenter, M. and Rapson, R.L. (2014) Emotional Contagion as a Precursor to Collective Emotions. Collective Emotions: 108. Oxford University Press, Oxford.

[171] McCraty, R., Atkinson, M. and Bradley, R.T. (2004) Electrophysiological Evidence of Intuition: Part 1. The Surprising Role of the Heart. The Journal of Alternative \& Complementary Medicine, 10, 133-143. http://dx.doi.org/10.1089/107555304322849057

[172] Banaclocha, M.A., Bókkon, I. and Banaclocha, H.M. (2010) Long-Term Memory in Brain Magnetite. Medical Hypotheses, 74, 254-257.

[173] Ekman, P. (1999) Basic Emotions. In: Dalgleish, T. and Power, M.J., Eds., Handbook of Cognition and Emotion, John 
Wiley \& Sons, Ltd., Sussex.

[174] Hugenberg, K. and Bodenhausen, G. (2003) Facing Prejudice: Implicit Prejudice and the Perception of Facial Threat. Psychological Science, 14, 640-643. http://dx.doi.org/10.1046/j.0956-7976.2003.psci_1478.x

[175] Calder, A., Lawrence, A. and Young, A. (2001) Neuropsychology of Fear and Loathing. Nature Reviews. Neuroscience, 2, 353-363.

[176] Wheeler, M. and Fiske, S. (2005) Controlling Racial Prejudice Social-Cognitive Goals Affect Amygdala and Stereotype Activation. Psychological Science, 16, 56-63. http://dx.doi.org/10.1111/j.0956-7976.2005.00780.x

[177] Gollisch, T. and Meister, M. (2010) Eye Smarter than Scientists Believed: Neural Computations in Circuits of the Retina. Neuron, 65, 150-164. http://dx.doi.org/10.1016/j.neuron.2009.12.009

[178] Persinger, M.A. (2006) A Potential Multiple Resonance Mechanism by Which Weak Magnetic Fields Affect Molecules and Medical Problems: The Example of Melatonin and Experimental "Multiple Sclerosis". Medical Hypotheses, 66, 811-815. http://dx.doi.org/10.1016/j.mehy.2005.09.044

[179] Munsky, B., Trinh, B. and Khammash, M. (2009) Listening to the Noise: Random Fluctuations Reveal Gene Network Parameters. Molecular Systems Biology, 5, 318. http://dx.doi.org/10.1038/msb.2009.75

[180] Sandyk, R. and Derpapas, K. (1994) The Effects of Picotesla Range Magnetic Fields on Visuospatial Functions in Multiple Sclerosis. International Journal of Neuroscience, 78, 103-109. http://dx.doi.org/10.3109/00207459408986292

[181] Richardson, K., Imhoff, T., Grigg, P. and Collins, J. (1998) Using Electrical Noise to Enhance the Ability of Humans to Detect Subthreshold Mechanical Cutaneous Stimuli. Chaos, 8, 599-603. http://dx.doi.org/10.1063/1.166341

[182] Mueller, S., Wang, D., Fox, M., Yeo, B., Sepulcre, J., Sabuncu, M., Shafee, R., Lu, J. and Liu, H. (2013) Individual Variability in Functional Connectivity Architecture of the Human Brain. Neuron, 77, 586-595. http://dx.doi.org/10.1016/j.neuron.2012.12.028

[183] Vanderhasselt, M.A., Baeken, C., Van Schuerbeek, P., Luypaert, R. and De Raedt, R. (2013) Inter-Individual Differences in the Habitual Use of Cognitive Reappraisal and Expressive Suppression Are Associated with Variations in Prefrontal Cognitive Control for Emotional Information: An Event Related fMRI Study. Biological Psychology, 92, 433439. http://dx.doi.org/10.1016/j.biopsycho.2012.03.005

[184] Davies, D.R., Matthews, G., Stammers, R.B. and Westerman, S.J. (2013) Human Performance: Cognition, Stress and Individual Differences. Psychology Press, Hove, East Sussex.

[185] Adamatsky, A. (2005) Dynamics of Crowd Minds, Patterns of Irrationality in Emotions, Beliefs and Actions. World Scientific Publishing Co. Pte. Ltd., Singapore.

[186] Bajpai, R.P. (2003) Quantum Coherence of Biophotons and Living Systems. Indian Journal of Experimental Biology, 41, 514-527.

[187] Popp, F.A., Maric-Oehler, W., Schlebusch, K.P. and Klimek, W. (2005) Evidence of Light Piping (Meridian-Like Channels) in the Human Body and Nonlocal EMF Effects. Electromagnetic Biology and Medicine, 24, 359-374. http://dx.doi.org/10.1080/15368370500381760

[188] Fillaux, F. (2005) Quantum Entanglement and Nonlocal Proton Transfer Dynamics in Dimers of Formic Acid and Analogues. Chemical Physics Letters, 408, 302-306. http://dx.doi.org/10.1016/j.cplett.2005.04.069

[189] Zotter, S., Ma, X.S., Kofler, J., Ursin, R., Jennewein, T., Brukner, C. and Zeilinger, A. (2012) Experimental DelayedChoice Entanglement Swapping. Nature Physics, 8, 479-484.

[190] Raafat, R.M., Chater, N. and Frith, C. (2009) Herding in Humans. Trends in Cognitive Sciences, 13, 420-428.

[191] Jensen, O., Gips, B., Bergmann, T.O. and Bonnefond, M. (2014) Temporal Coding Organized by Coupled Alpha and Gamma Oscillations Prioritize Visual Processing. Trends in Neurosciences, 37, 357-369. http://dx.doi.org/10.1016/j.tins.2014.04.001

[192] Sulis, W. (2008) Stochastic Phase Decoupling in Dynamical Networks. Nonlinear Dynamics, Psychology, and Life Sciences, 12, 327-357.

[193] Haegens, S., Luther, L. and Jensen, O. (2012) Somatosensory Anticipatory Alpha Activity Increases to Suppress Distracting Input. Journal of Cognitive Neuroscience, 24, 677-685.

[194] Mansteadc, A.S. (2014) Social Appraisal as a Cause of Collective Emotions. In: von Scheve, C. and Salmela, M., Eds., Collective Emotions: 141, OUP, Oxford.

[195] Mawson, A.R. (2005) Understanding Mass Panic and Other Collective Responses to Threat and Disaster. Psychiatry: Interpersonal and Biological Processes, 68, 95-113. http://dx.doi.org/10.1521/psyc.2005.68.2.95

[196] Lakin, J.L., Jefferis, V.E., Cheng, C.M. and Chartrand, T.L. (2003) The Chameleon Effect as Social Glue: Evidence for the Evolutionary Significance of Nonconscious Mimicry. Journal of Nonverbal Behavior, 27, 145-162. http://dx.doi.org/10.1023/A:1025389814290 
[197] Engel, A., Fries, P. and Singer, W. (2001) Dynamic Predictions: Oscillations and Synchrony in Top down Processing. Nature Reviews Neuroscience, 2, 704-715. http://dx.doi.org/10.1038/35094565

[198] Gomez-Ramirez, M., Kelly, S., Molholm, S., Sehatpour, P., Schwartz, T. and Foxe, J. (2011) Oscillatory Sensory Selection Mechanisms during Intersensory Attention to Rhythmic Auditory and Visual Inputs: A Human Electrocorticographic Investigation. The Journal of Neuroscience, 31, 18556-18567. http://dx.doi.org/10.1523/JNEUROSCI.2164-11.2011

[199] Badzey, R. and Mohanty, P. (2005) Coherent Signal Amplification in Bistable Nanomechanical Oscillators by Stochastic Resonance. Nature, 437, 995-998. http://dx.doi.org/10.1038/nature04124

[200] Gluckman, B., Netoff, T., Neel, E., Ditto, W., Spano, M. and Schiff, S. (1996) Stochastic Resonance in a Neuronal Network from Mammalian Brain. Physical Review Letters, 77, 4098. http://dx.doi.org/10.1103/PhysRevLett.77.4098

[201] Persinger, M.A. (2014) Schumann Resonance Frequencies Found within Quantitative Electroencephalographic Activity: Implications for Earth-Brain Interactions. International Letters of Chemistry, Physics and Astronomy, 11, 24-32.

[202] Usher, M. and Feingold, M. (2000) Stochastic Resonance in the Speed of Memory Retrieval. Biological Cybernetics, 83, L011-L016. http://dx.doi.org/10.1007/PL00007974

[203] Guastello, S., Pincus, D. and Gunderson, P.R. (2006) Electrodermal Arousal between Participants in a Conversation: Nonlinear Dynamics and Linkage Effects. Nonlinear Dynamics, Psychology and Life Sciences, 10, 365-399.

[204] Wibral, M., Rahm, B., Rieder, M., Lindner, M., Vicente, R. and Kaiser, J. (2011) Transfer Entropy in Magnetoencephalographic Data: Quantifying Information Flow in Cortical and Cerebellar Networks. Progress in Biophysics and Molecular Biology, 105, 80-97. http://dx.doi.org/10.1016/j.pbiomolbio.2010.11.006

[205] Salis, H. and Kaznessis, Y. (2005) Accurate Hybrid Stochastic Simulation of a System of Coupled Chemical or Biochemical Reactions. The Journal of Chemical Physics, 122, Article ID: 054103. http://dx.doi.org/10.1063/1.1835951

[206] Hu, H. and Wu, M. (2004) Action Potential Modulation of Neural Spin Networks Suggests Possible Role of Spin. Neuroquantology, 2.

[207] Hameroff, S., Nip, A., Porter, M. and Tuszynski, J. (2002) Conduction Pathways in Microtubules, Biological Quantum Computation, and Consciousness. Biosystems, 64, 149-168. http://dx.doi.org/10.1016/S0303-2647(01)00183-6

[208] Craddock, T.J.A., Friesen, D., Mane, J., Hameroff, S. and Tuszynski, J.A. (2014) The Feasibility of Coherent Energy Transfer in Microtubules. arXiv preprint arXiv:1405.3170.

[209] Penrose, R. and Hameroff, S. (2011) Consciousness in the Universe: Neuroscience, Quantum Space-Time Geometry and Orch OR Theory. Journal of Cosmology, 14, 1-17.

[210] Craddock, T.J., Tuszynski, J.A. and Hameroff, S. (2012) Cytoskeletal Signaling: Is Memory Encoded in Microtubule Lattices by CaMKII Phosphorylation? PLoS Computational Biology, 8, Article ID: e1002421. http://dx.doi.org/10.1371/journal.pcbi.1002421

[211] Ilin, R. and Kozma, R. (2006) Stability of Coupled Excitatory-Inhibitory Neural Populations and Application to Control of Multi-Stable Systems. Physics Letters A, 360, 66-83. http://dx.doi.org/10.1016/j.physleta.2006.07.050

[212] Hameroff, S.R. and Penrose, R. (1996) Conscious Events as Orchestrated Space-Time Selections. Journal of Consciousness Studies, 3, 36-53.

[213] Hameroff, S. (1998) Quantum Computation in Brain Microtubules? The Penrose-Hameroff' Orch OR'model of Consciousness. Philosophical Transactions of Royal Society of London Series A: Mathematical Physical and Engineering Sciences, 1869-1895.

[214] Bohm, D. and Hiley, B.J. (1993) The Undivided Universe. Routledge, London.

[215] Hameroff, S.R. (2007) The Brain Is both Neurocomputer and Quantum Computer. Cognitive Science, 31, $1035-1045$. http://dx.doi.org/10.1080/03640210701704004

[216] Persinger, M.A., et al. (2013) Congruence of Energies for Cerebral Photon Emissions, Quantitative EEG Activities and $\sim 5$ nT Changes in the Proximal Geomagnetic Field Support Spin-Based Hypothesis of Consciousness. Journal of Consciousness Exploration \& Research, 4.

[217] Hameroff, S. (2014) Consciousness, Microtubules, \& 'Orch OR’: A 'Space-Time Odyssey’. Journal of Consciousness Studies, 21, 126-153.

[218] Georgiev, D. and Glazebrook, J. (2006) Dissipationless Waves for Information Transfer in Neurobiology—Some Implications. Informatica, 30, 221-232.

[219] Freeman, W., Kozma, R. and Werbos, P. (2001) Biocomplexity: Adaptive Behavior in Complex Stochastic Dynamical Systems. BioSystems: Journal of Biological and Information Processing Sciences, 59, 109-123.

[220] Maeda, K.I., Misonoh, Y. and Kobayashi, T. (2010) Oscillating Universe in Hořava-Lifshitz Gravity. Physical Review D, 82, Article ID: 064024. http://dx.doi.org/10.1103/PhysRevD.82.064024 
Scientific Research Publishing (SCIRP) is one of the largest Open Access journal publishers. It is currently publishing more than 200 open access, online, peer-reviewed journals covering a wide range of academic disciplines. SCIRP serves the worldwide academic communities and contributes to the progress and application of science with its publication.

Other selected journals from SCIRP are listed as below. Submit your manuscript to us via either submit@scirp.org or Online Submission Portal.
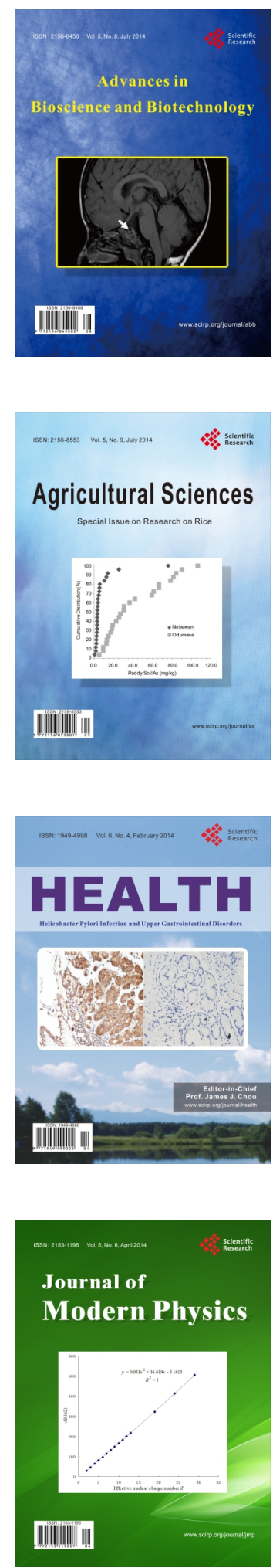
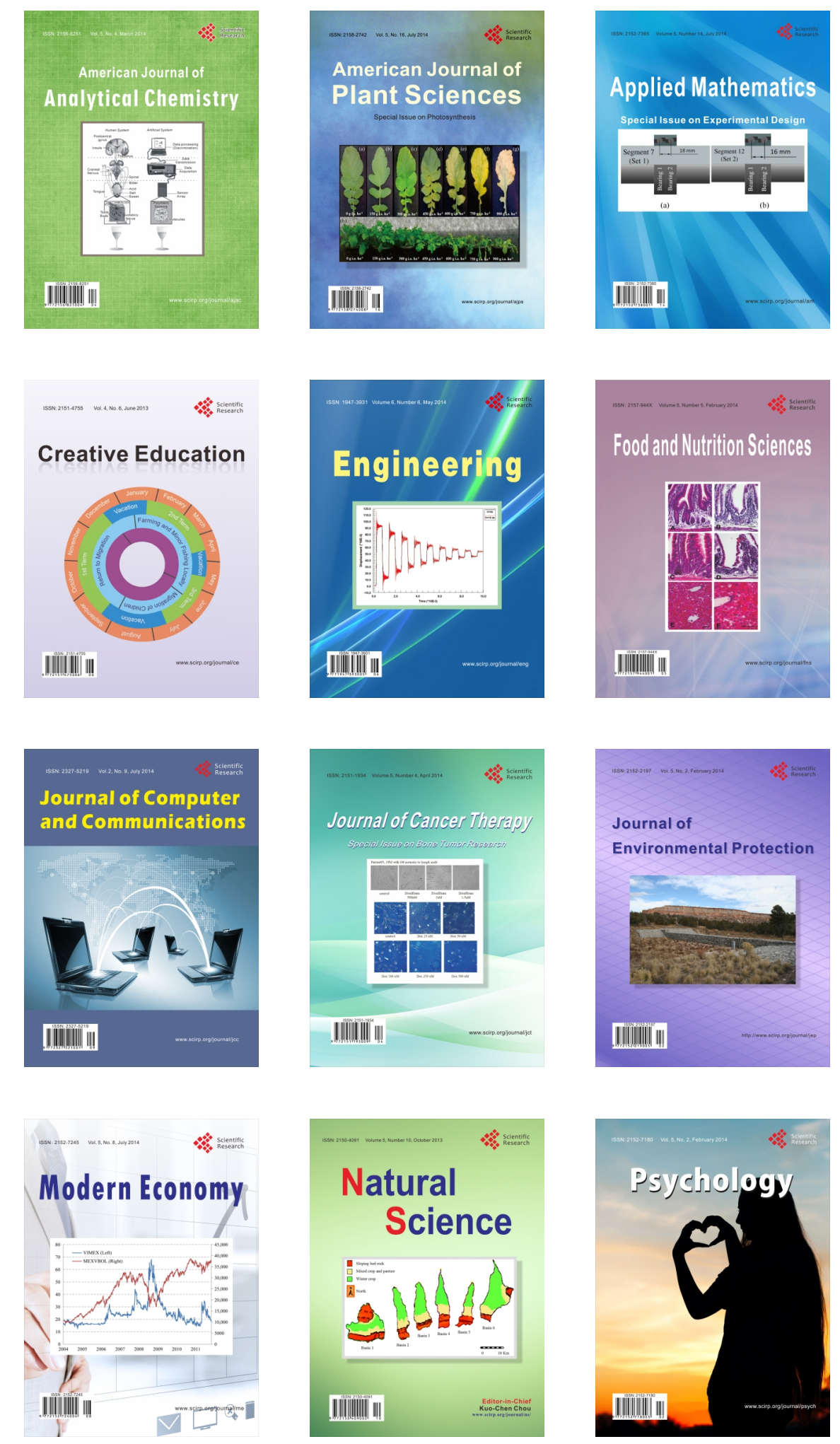